\title{
Electric vehicles: battery capacity, charger power, access to charging and the impacts on distribution networks
}

\author{
James Dixon, Keith Bell
}

Dept. of Electronic and Electrical Engineering, University of Strathclyde, Glasgow, UK

\begin{abstract}
The battery electric vehicle $(\mathrm{EV})$ market is in a state of continuing rapid evolution, both in terms of the battery capacities and charger power ratings that vehicle manufacturers are bringing to the market and the increasingly widespread penetration of charging infrastructure. As a result, individuals' charging behaviours may change substantially and be different from what has been expected or observed to date. This could have a significant effect on the resulting electrical demand from EV charging. Aside from these technical parameters, the demographics of the population served by any given network - and how that might affect their travel habits, particularly car use - must be considered. In this paper, statistical analysis of a large travel survey dataset is carried out to support the hypothesis that car use is likely to vary according to population demographics. Car-based travel diaries disaggregated on key demographic traits of the drivers are assigned to vehicles in the network according to Census data pertaining to those same demographic traits. Charging schedules are derived from these travel diaries for different battery capacities, charger power ratings and level of access to charging to investigate the likely effect of changing these parameters on the resulting charging behaviour and electricity demand. It is found that out of the key emerging patterns identified in the evolving EV market, increasing battery capacities and the establishment of more widespread charging opportunities may reduce the peak demand from EV charging or shift it to a time less likely to coincide with peak domestic demand, hence making it easier for the network to cope with increasing penetrations of EVs. On the other hand, increasing charging power may increase the peak and bring it closer to a time where it is more likely to coincide with peak domestic demand.
\end{abstract}


Keywords: Electric vehicles, Distribution network, Charging

\section{Nomenclature}

\section{Sets}

$\mathbb{B} \quad$ Set of busbars in distribution network, indexed by $b$

$\mathbb{E}_{h} \quad$ Set of EVs at household $h$, indexed by $e$

$\mathbb{H}_{b} \quad$ Set of households at busbar $b$, indexed by $h$

\section{Variables}

$\Delta E_{i} \quad$ Change in EV energy storage from charging event following trip $i$

$\lambda_{i} \quad$ Decay constant for constant voltage region of lithium ion charging curve, during charge event following trip $i$

$E^{\text {start }}, E^{\text {end }} \mathrm{EV}$ energy storage content at start of charging event following trip $i$, EV energy storage content at end of charging event following trip $i$

$P_{i}(t)$ Instantaneous power demand at time $t$ (minutes) after the plug-in time during charge event following trip $i$

$P_{i}^{D C} \quad$ Maximum rated DC charging power available during charge event following trip $i$

$S^{\text {min }}, S_{i}$ Minimum allowable EV battery state of charge, EV battery state of charge after trip $i$, including any parked and/or en route charging after and/or during the trip

$t_{i}^{0.8}, t_{i}^{\infty}$ Time at which vehicle reaches state of charge of $0.8 \mathrm{in}$ parked charging event following trip $i$, time at which the charging power reaches a value close to zero (taken as $1 \%$ of the maximum rated power) in parked charging event following trip $i$

$t_{i}^{s}, t_{i}^{d}$ Time at which vehicle starts parked charging event following trip $i$, time at which vehicle departs parked charging event following trip $i$ 


\section{Introduction}

Battery electric vehicles (EVs) are cited as a key contributor to a reduction in carbon dioxide emissions and air pollution by governments worldwide, from the UK [1] to China [2] and the US [3]. However, concerns have been raised about the impact of widespread EV uptake and the subsequent charging at peoples' homes, where the capacity of existing distribution networks may not be able to cope with the increase in demand, by electricity network owners [4], regulators [5] and policymakers [6-8]. The extent and timing of the need for intervention is highly uncertain; this is exacerbated by two factors as addressed in this paper: (i) the rapidly evolving EV market with the associated change in key vehicle parameters, and (ii) the demographic make-up of the individuals that are driving the EVs.

\subsection{Electric Vehicle Parameters and the Rapidly Evolving Market}

\subsubsection{Battery Capacity}

Based on a review of the pace of change of the EV market in recent years, it seems that battery capacities are increasing. Battery capacities typical in 'affordable' EVs as recently as 2016 were typically of the order 16-24 kWh: for example, the 2011-2015 Nissan Leaf (24 kWh) [9], the 2012-2016 Renault Zoe (22 kWh) [10] and the 2009-2016 Mitsubishi i-MiEV (16 kWh) [11]. More recently, the 2018-present Nissan Leaf has a $40 \mathrm{kWh}$ battery as standard and the 2016-present Renault Zoe has a $41 \mathrm{kWh}$ configuration as standard. New models are being launched, such as the 2019 Hyundai Kona Electric [12] and 2019 Tesla Model 3 [13], which at 64 and $60 \mathrm{kWh}$ respectively are fairly longrange vehicles but remain towards the lower end of the EV market in terms of price, with post-subsidy UK prices of $£ 32,845$ and $£ 38,800$ respectively. Volkswagen is launching their ID3 EV in 2020 with a configurations between 45-77 kWh at a starting price 'less than $£ 25,848$ ' [14]. Compared to the Tesla Model S (2012-present), a long-established long range EV model with prices starting at $£ 75,500$ in the UK after subsidies [15], it seems the prices of EVs with large batteries are falling consistently with the general fall in the cost of lithium ion batteries [16].

It is hypothesised that due to their greater driving range, vehicles with larger battery capacities could be expected to seek fewer charging opportunities than those with smaller battery capacities. The knock-on effect of this would be that the energy requirement of those charge events would be 
greater. The extent to which these effects will impact the power system is uncertain.

\subsubsection{Charger Power}

Charging power also seems to be increasing. In terms of charging power at peoples' homes, a move from 'slow' (16 A @ $230 \mathrm{~V} \approx 3.7 \mathrm{~kW}$ ) to 'fast' (32 $\mathrm{A} @ 230 \mathrm{~V} \approx 7.4 \mathrm{~kW}) \mathrm{AC}$ charging seems likely: whereas first generation EVs such as the 2011-2015 Nissan Leaf [9] and the 2009-2016 Mitsubishi iMiEV (16 kWh) [11] could only accept 'slow' AC charging, all new generation EVs referenced in the preceding section are rated for 'fast' $\mathrm{AC}$ charging. Furthermore, as there is generally no difference in price between a 'slow' and a 'fast' AC charger (for example, the WallPod EV charger retails at $£ 320$ in the UK for either 16 or 32 A configuration [17]), it could be reasonably expected that most consumers would opt for the high power rating option.

While a switch to DC charging has been discussed in the literature such as [18], in which it is discussed how switching to DC charging and consequential removal of on-board $\mathrm{AC} / \mathrm{DC}$ converters could (i) reduce the up-front cost of the vehicle and (ii) increase charging efficiency - for the near future $\mathrm{AC}$ charging at the above rates is expected to remain dominant. The charging rates based on 16/32 A cables given above are from the SAE J1772 charging standard detailed in [19].

It is hypothesised that having access to a higher charger power is likely to increase the charging demand peak; however, the extent to which this may happen is uncertain.

\subsubsection{Charging Access}

It also seems likely that future EV users will have access to charging at more locations. [20] and [21] have suggested that EV drivers are likely to actively seek out destinations that offer charging opportunities, even at the expense of lengthening their own journeys. This explains the recent and ongoing growth in free-to-use public charging infrastructure, installed by business owners as a way of attracting additional custom. As of August 2019, three of the UK's biggest supermarket chains (Tesco, Morrisons and Lidl) have announced plans to install free-to-use EV charging infrastructure at their stores [22-24], highlighting a recognition by businesses who provide parking of the draw that can be offered by EV charging facilities.

It is hypothesised that having access to charging at more locations will reduce the stress on the distribution network that serves home charging. 
However, the amount to which this may happen is uncertain, as is the effect of having charging available at particular locations (e.g. the effect of charging at work vs. the effect of charging at public destinations).

\subsection{Variation in Car Use within a Population}

The distance driven by individuals, the frequency of their trips and the times at which they arrive home are particularly important factors for the consideration when quantifying likely EV charging demand, as they effectively determine the energy and peak power demand on the network. Travel habits are diverse across a population of individuals, and it has been documented in [25-27] that income, employment status and geographical location have a significant impact on the travel habits, including the car use, of individuals. Therefore, aside from the technical specifications of the EVs charging within a network, one must also consider the variation of car use within that network. As this is addressed as a key gap in the existing academic literature (section 1.3), a motivation for this paper is to characterise the impact of EV charging on electricity networks with consideration of the demographics of the population that is served by the network in question.

\subsection{Relevant Literature}

The characterisation of EV charging demand on distribution networks is a well-researched area of the academic literature. There have been many works based on the analysis of travel survey data - that is, self-reported data pertaining to the location, distance and duration of individuals' trips - to simulate the arrival time and energy demand of a fleet of EVs, and thus derive their likely charging schedules. The governing assumption in these works is that if internal combustion vehicles $(\mathrm{ICVs})$ were replaced with EVs, the trips made by the individuals driving the vehicles would be unchanged. [28] uses results from a US-based travel survey [29] to return probability distributions of the arrival time of vehicles following a day of driving. Although the start time of charge events are based on real data, the energy requirement is based on the simple assumption that vehicles begin charging with a battery State of Charge (SoC) sampled from a Gaussian distribution centred on 50\% . [30] and [31] simulate EV charging based on distributions of the time at which the EV arrives at home (and hence starts charging) and the daily distance driven (and hence the energy required from charging based on a fixed rate of consumption) from statistical analysis of the UK Time Use Survey (TUS) and the US National Household Travel Survey (NHTS) respectively. [32] 
uses Origin-Destination analysis to set origin and destination zones of each EV's journey based on statistical analysis of travel survey data; the distance between the two - used to derive the energy requirement of charging - is sampled from a Gaussian distribution centred on the straight line distance between the centroids of the zones. [33] applies a clustering technique to results of the Dutch travel survey (Mobiliteitsonderzoek Nederland) to produce 25 archetypal driving behaviours, from which probability distributions of the arrival time and charging energy requirement are returned. [34] uses a Gaussian Copula method to tie together the separate distributions of the time a vehicle leaves home, the time a vehicle arrives home and the overall distance it travels during the day (from which the charging energy requirement is derived) from the same Dutch travel data as [33]. While [28, 30-34] only consider one driving day, [35] uses data from the week-long US NHTS to simulate EV charging behaviour on the basis of every travel diary in the dataset, hence giving a week-long charging demand profile that attempts to reflect day-to-day driving behaviour.

Within the last decade, publicly funded EV trial projects have been completed with the aim of providing an insight into the driving and charging habits of EV users. Several works have been carried out that use the results of these trials to derive probability distributions of charging start time and energy requirement. In [36], data from the British EV trial 'Plugged In Midlands' is used as a basis for clustering of EV demand profiles and a risk assessment of the violation of network limits following the electrification of a fleet of private vehicles displaying the same charging behaviour as in the trial. In [37], data from Newcastle University's SwitchEV project is used to build a stochastic simulation of the impact of EV charging on a real distribution network feeder. [38] uses an Irish EV trial dataset to simulate charging profiles of a fleet of EVs that may have access to charging at a variety of locations over the course of two days, thus capturing the effect of charging events on subsequent driving and charging behaviour.

The use of EV trial data holds two distinct advantages over the use of travel data. Firstly, whereas it has been shown that the adoption of EVs changes driver behaviour [39, 40], the use of travel data based on ICVs will fail to catch any EV-specific behaviour. Secondly, the application of ICV travel data ${ }^{1}$ to a fleet of EVs may not be feasible, given EVs' generally lower

\footnotetext{
${ }^{1}$ Though there is no $\mathrm{EV} / \mathrm{ICV}$ classification available in the NTS dataset, it can be
} 
driving range. However, a major limitation to using EV trial data is that they are generally tied to a particular set of technologies and/or individuals. For example, the trial datasets used in [36-38] concern vehicles with battery capacities in the range 16-24 kWh and 'slow' charging of 3-4 kW. The rapid changes in the EV market in terms of battery capacity and charger power as discussed in section 1.1 mean that these datasets can become out of date. As the research contribution made by this paper is to provide a quantification of the likely effect of changing these parameters, the use of EV trial data is not appropriate. Furthermore, the trial participants tend to be self-selecting and are more likely to be of certain socio-economic backgrounds: for example, in the SwitchEV trial, participants had to pay a $£ 220 /$ month fee to be in trial, be home owners with off-street parking and satisfy insurance criteria [42]. Therefore, it is argued that using data from these trials risks capturing behaviour from only a subset of societal segments.

The majority of works in the literature focus on integrating EV demand models with distribution networks, where they are expected to cause the greatest impact [43]. With the exception of [34-36, 38], all of the other works reviewed [28, 30-33, 37, 44-49] involve some level of simulation of EV charging and the superposition of this demand onto a model of a distribution network.

All of the works in $[28,31,33,44,46,47]$ use simple, generic distribution networks (for example, one of a number of IEEE distribution test feeders [50]) to model the impact of EV charging. While the use of these generic test feeders can provide a valuable base to develop and test a model, it is suggested that the area-specific, often historical design features of electrical networks are likely to have a significant effect on the impact seen by the network from EV charging and therefore the use of generic test feeders is prone to misrepresentation of the issues that may arise in real networks.

To this effect, there are works that have looked to simulate EV charging demand on real networks. [45] presents analysis of part of a real distribution network, though it only consists of a single LV feeder serving 135 households. [48] presents work on a much larger area of a real LV network serving over 6,000 customers and [49] uses a representation of a network serving over

assumed for practical purposes to be entirely ICV-based due to the relative infancy of EVs and their low penetration in the market - for example, in the UK they represented $0.2 \%$ of the total vehicle fleet in 2016 [41], the latest year for which NTS data is currently available. 
10,000 endpoints on the Danish island of Bornholm. In using such large networks, the latter two $[48,49]$ assign EV loads to households deterministically. In contrast, [37] presents Monte Carlo analysis of EV charging on a real GB distribution network serving 288 households which can be used to show the variation in expected charging behaviour. While the electrical characteristics of real distribution networks are captured in all the works discussed [37, 45, 48, 49], the demographic characteristics are left out: simple, fixed assumptions are made as to the rate of EV penetration in the networks and there is no disaggregation of likely travel habits within a population.

\subsection{Contribution}

A review of the relevant literature (section 1.3) has shown that while this area of research is already well practised, there remain gaps in the collective knowledge.

All the papers discussed in section 1.3 assume that when a vehicle arrives at a location where it can charge, it will always charge - regardless of its current level of energy storage or its future travel requirements. It is proposed that this is an important and potentially risky assumption to make: for example, the Electric Nation EV trial published in July 2019 found that individuals would often go for days without charging, despite using their cars every day and having access to a charger at home. The study found that this was especially true for EVs with larger batteries: those with capacities above $35 \mathrm{kWh}$ chose to charge on average every 3.2 days, versus every 1.5 days for those with capacities under $25 \mathrm{kWh}$ [51]. To address this important point, the work presented in this paper models drivers' likely charging schedules derived from week-long travel diaries, using a heuristic method originally presented in [52], in which the focus is to minimise the number of charging events (and the associated inconvenience) subject to meeting the energy requirements of a predefined set of journeys.

All of the works that attempt to characterise EV charging demand on distribution networks use simplistic assumptions about the spread of EVs in a network and their charging or travel habits. In this paper, a fleet of EVs is simulated within an electrical distribution network according to the spatial distribution of existing vehicles according to Census data. Each vehicle is assigned a week-long travel diary from the UK National Travel Survey (NTS) based on key demographic attributes of the driver found from Census data, and these travel diaries are used to derive charging schedules from the 
heuristic presented in [52] as already mentioned. By modelling the heterogeneity in travel habits amongst a population and the resulting demand from EV charging, it is suggested that this approach can contribute to a better understanding of the area and network-specific impacts of the electrification of private transport.

The rest of this paper is organised as follows. Section 2 presents a description of the EV parameters included in this study. Section 3 presents statistical analysis of the UK NTS dataset to support the hypothesis that population demographics are likely to have an impact on EV charging demand. In section 4, the distribution network model is presented and it is explained how this model is integrated with the NTS data and UK Census data to produce a socio-technical model for evaluating the likely impact of EV charging on a given network serving a given population. Section 5 explains how charging schedules are derived on the basis of NTS travel diaries. Section 6 presents the key results from this study, which are discussed in section 7 . Conclusions are drawn and suggestions for future work are made in section 8 .

\section{Electric Vehicle Charging Parameters}

The effect of EV parameters on the resulting charging demand is investigated by considering three representative EV models, as detailed in Table 1. The battery capacities span possible values present in the EV market, based on three representative vehicles: the Nissan Leaf 2011-2015 (24 kWh), Hyundai Kona Electric 642019 (64 kWh) and Tesla Model S 1002012 (100 $\mathrm{kWh}$ ). The energy consumption values (which determines how the vehicles choose charging events, further described in section 5) are taken from the US Environmental Protection Agency (EPA)'s fuel economy test data ${ }^{2}$ [54] for those vehicles.

\footnotetext{
${ }^{2}$ The EPA's Federal Test Procedure is designed to allow direct comparison of emissions and fuel economy between different vehicles for real-world driving conditions based on city and highway driving cycles. These figures tend to be more conservative than European data, which unlike in the US, result from tests carried out by manufacturers themselves. This is likely to have been a key contributing factor in the 'Dieselgate' scandal 2015-present [53].
} 
Table 1: Key parameters relating to three EV models as used in this study

\begin{tabular}{|c|c|c|c|}
\hline EV & 1 & 2 & 3 \\
\hline Battery capacity (kWh) & 24 & 64 & 100 \\
\hline \multicolumn{4}{|c|}{ Energy consumption $(\mathrm{kWh} / \mathrm{km})$} \\
\hline City & 0.17 & 0.16 & 0.24 \\
\hline Combined & 0.19 & 0.18 & 0.23 \\
\hline Highway & 0.21 & 0.19 & 0.23 \\
\hline \multicolumn{4}{|c|}{ Charger power $(k W)$} \\
\hline Home (AC) & $3.7 / 7.4$ & $3.7 / 7.4$ & $3.7 / 7.4$ \\
\hline Workplace, public (AC) & $11 / 22$ & $11 / 22$ & $11 / 22$ \\
\hline En route $(\mathrm{DC})$ & $50 / 150$ & $80 / 300$ & $120 / 300$ \\
\hline
\end{tabular}

The effect of varying charger power is investigated by using 'low' and 'high' power scenarios. The low power scenario is based on 'slow' home charging (single phase $16 \mathrm{~A}, 230 \mathrm{~V}$ ) and workplace/public destination charging (three phase $16 \mathrm{~A}, 230 \mathrm{~V}$ ); en route charging rate are based on the max DC charging ratings of the three representative vehicles above [9, 12, 15]. The high power scenario is based on 'fast' home charging (single phase 32 A, $230 \mathrm{~V}$ ) and workplace/public destination charging (three phase $32 \mathrm{~A}, 230$ $\mathrm{V})$; en route charging rates are based on projected near-future developments as previously discussed in section 1.1.3.

The effect of varying level of access to charging was investigated by simulating four levels of access to charging at different locations: home only, home \& work, home \& public and home, work \& public. Public charging opportunities are defined from the following set of trip destinations, as stated in the NTS data: food shopping, non food shopping, eat/drink with friends, day trip, sport: participate, personal business eat/drink, other social, entertain/public activity, personal business other, personal business medical. Public charging opportunities are not available at the end of escort journeys (where the main purpose of the journey is driving another individual somewhere).

\section{Statistical Analysis of Car-Based Travel Diaries from the UK National Travel Survey}

\subsection{Overview}

The UK National Travel Survey is conducted annually for around 15,000 residents. Data is gathered via a face-to-face interview and a self-completed diary for all trips taken over a 7-day period [55]. The 7-day period recorded 
differs between the individuals recording the data, hence minimising any bias from seasonal effects and holidays. The resulting dataset for the years 2002-2016 as used in this study contains 101,214 week-long travel diaries of car-based trips (i.e. any trip made in any other mode of transport was removed), which have been aligned such that they all take place from 00:00 on Monday to 23:59 on Sunday. Key data fields for all car-based trips in an example NTS travel diary are shown in Table 2.

Table 2: Example UK NTS travel diary (car-based trips)

\begin{tabular}{llllll}
\hline $\begin{array}{l}\text { Trip } \\
\#\end{array}$ & Origin & Destination & Trip Start & Trip End & $\begin{array}{l}\text { Distance } \\
\text { (miles) }\end{array}$ \\
\hline 1 & Home & Work & M 07:20 & M 08:00 & 25 \\
2 & Work & Home & M 18:30 & M 19:20 & 25 \\
3 & Home & Entertain & M 20:15 & M 20:40 & 12 \\
4 & Entertain & Home & M 22:30 & M 23:00 & 12 \\
5 & Home & Work & Tu 07:20 & Tu 08:00 & 25 \\
6 & Work & Home & Tu 18:10 & Tu 19:00 & 25 \\
7 & Home & Work & Th 14:30 & Th 15:10 & 25 \\
8 & Work & Home & Th 18:20 & Th 19:00 & 25 \\
9 & Home & Sport & Th 19:40 & Th 20:00 & 6 \\
10 & Sport & Home & Th 21:00 & Th 21:45 & 6 \\
11 & Home & Work & F 07:20 & F 08:00 & 25 \\
12 & Work & Home & F 18:20 & F 19:00 & 25 \\
13 & Home & Food shop & Sa 13:00 & Sa 14:00 & 5 \\
14 & Food shop & Home & Sa 16:00 & Sa 17:00 & 5 \\
15 & Home & Visit friends & Su 14:30 & Su 15:00 & 12 \\
16 & Visit friends & Home & Su 20:30 & Su 21:00 & 12 \\
\hline
\end{tabular}

\subsection{Disaggregation of National Travel Survey Travel Diaries on the Basis of Employment Type and Means of Travel to Work}

Aside from filling in a travel diary, NTS respondents also answer some questions about themselves. In this study, car-based travel diaries are disaggregated on the basis of the individual's employment type (employed, unemployed or self-employed) and their means of travel to work (car driver, car passenger, train, bus, bicycle, walk or did not answer (DNA) - i.e. unemployed/works from home). Table 3 shows the number of travel diaries by each combination of employment type and means of travel to work. By using UK Census data of the same fields, this is used to assign travel diaries to the fleet of EVs instantiated in the network that are likely to represent 
the travel habits of the individuals served by that network - this is further explained in section 4. Table 3 shows the number of NTS travel diaries by each combination of employment type and means of travel to work.

Table 3: Number of UK National Travel Survey (2002-2016) travel diaries by economic activity and means of travel to work category

\begin{tabular}{llllllll} 
& Train & Bus & $\begin{array}{l}\text { Mar } \\
\text { driver }\end{array}$ & $\begin{array}{l}\text { Car } \\
\text { pas- } \\
\text { senger }\end{array}$ & Bicycle & $\begin{array}{l}\text { On } \\
\text { foot }\end{array}$ & DNA \\
& & & & & & & \\
\hline $\begin{array}{l}\text { Employed } \\
\text { Self- }\end{array}$ & 2,444 & 967 & 46,158 & 734 & 1,234 & 2,989 & 32,806 \\
employed & 261 & 69 & 6,413 & 96 & 72 & 564 & 6,766 \\
Unemployed & 0 & 0 & 0 & 0 & 0 & 0 & 2,346 \\
\hline
\end{tabular}

The vast majority $(84.7 \%)$ of individuals who completed NTS travel diaries were in employment during the week of the survey, $11.6 \%$ were reportedly self-employed and the remaining $3.7 \%$ were unemployed. The latter all did not answer when asked their means of travel to work. Of the other economic activity types, there is shown to be an uneven spread of travel diaries between categories of means of travel to work, with car driver being by far the most reported: $54.4 \%$ of those in employment drove a car to work and $45.9 \%$ of those self-employed reported the same.

Of particular importance to impact of EVs' charging demand on a residential distribution network is the distance driven (and hence the energy requirement), the arrival time at home and the duration of the parking event. The following sections 3.2.1-3.2.3 present analysis of the differences in individuals' behaviour when aggregated on the basis of employment type and means of travel to work.

\subsubsection{Total Distance Covered in NTS Travel Diaries by Employment and Means of Travel to Work}

Figure 1 shows cumulative distribution functions (CDFs) for the total distance driven $(\mathrm{km})$ for all car-based trips in the NTS travel diaries by economic activity and means of travel to work. 

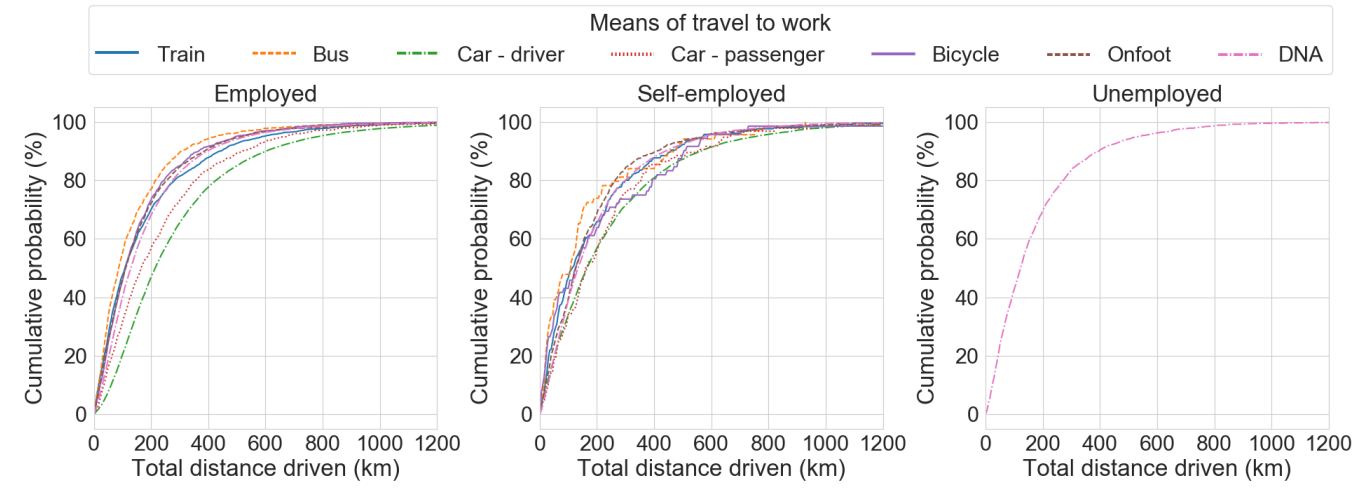

Figure 1: Cumulative distribution functions showing probability of car-based travel diaries exceeding given total distance $(\mathrm{km})$ by economic activity and means of travel to work

As shown in Figures 1, while there is no significant difference in the total distance or time driven by varying economic activity types, there does appear to be a difference by means of travel to work, with the car driver and car passenger classifications significantly more likely to drive further than those who take other means of transport to work. For example, whereas the median distance driven by all employed respondents who did not take a car to work (as either a driver or a passenger) is approximately $100 \mathrm{~km}$, the median distance driven by those who drove to work is over $200 \mathrm{~km}$. The self-employed curve is less smooth than the others because there are fewer data points (see Table 3).

\subsubsection{Parking Event Arrival Time in NTS Travel Diaries by Employment and Means of Travel to Work}

Figures 2 shows probability distribution functions (PDFs) for end time of any journey to home by economic activity and means of travel to work for weekday trips in 15 minute intervals. 

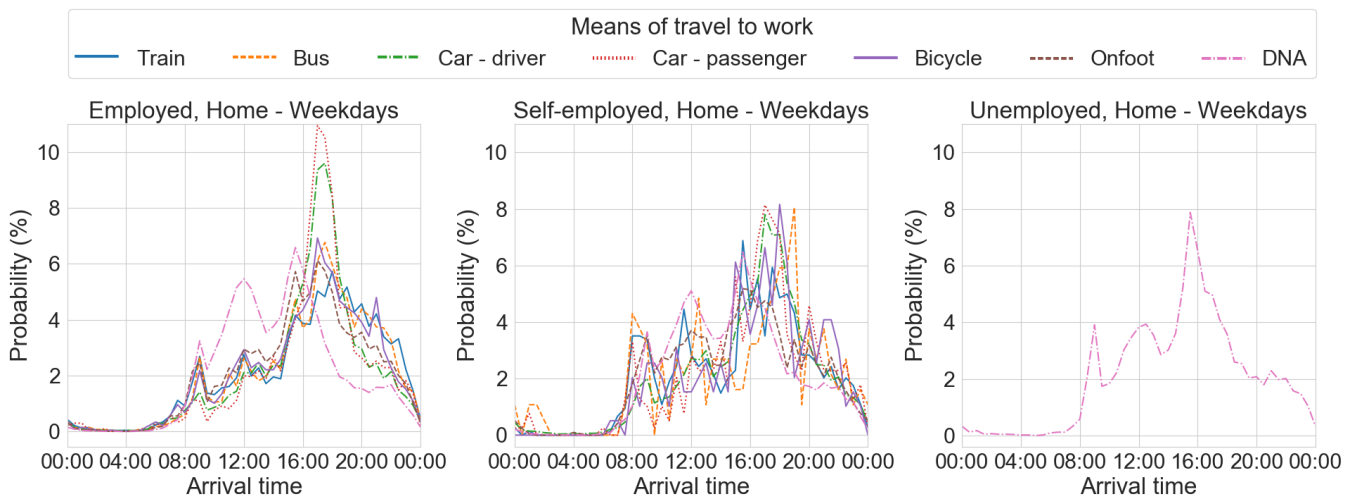

Figure 2: Probability density functions showing probability of home parking event arrival time by economic activity and means of travel to work for weekday car-based trips

Figure 2 shows characteristic spikes in arrival time in the evening around 17:00-19:00 as drivers arrive home from their daily activities; this behaviour is shown to be particularly apparent for employed individuals who use a car to get to work, either as driver or passenger. The self-employed dataset shows a less pronounced peak, but the highest values remain within the bounds of 17:00-19:00. Individuals reporting themselves as unemployed exhibit broadly similar behaviour to the other categories, though the peak in their arrival time at home is earlier than employed or self-employed individuals, in this case happening before 16:00.

\subsubsection{Parking Event Duration in NTS Travel Diaries by Employment and Means of Travel to Work}

Figures 3 shows CDFs for the parking event duration for all home-bound journeys from the NTS travel diaries by economic activity and means of travel to work. 

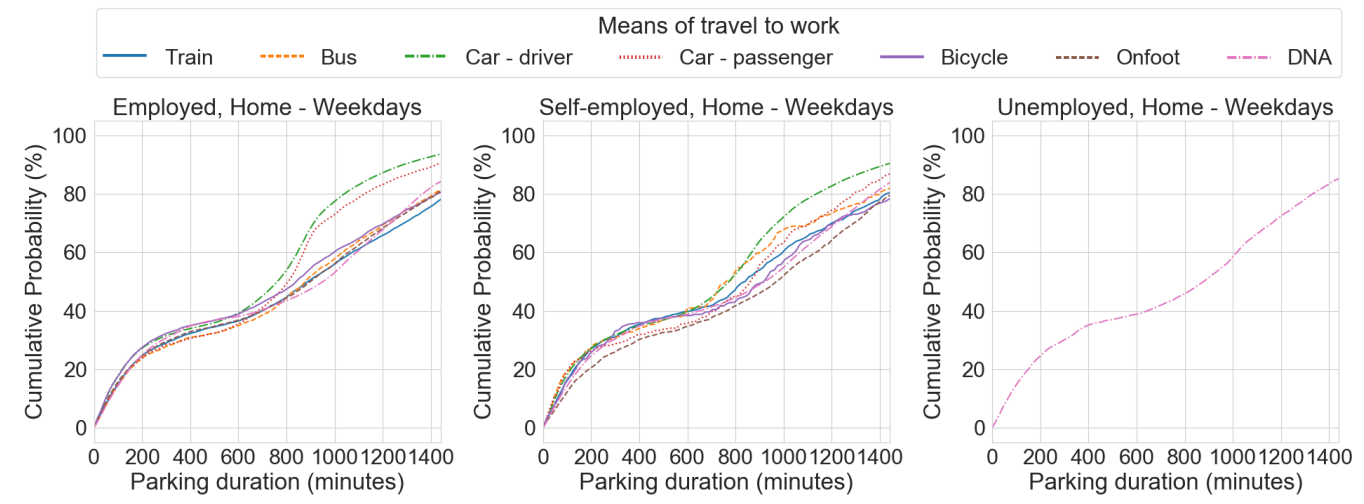

Figure 3: Cumulative distribution functions of parking event duration of car-based trips ending at home within NTS travel diaries by economic activity and means of travel to work - weekday trips

Figure 3 shows that individuals across all types of economic activity and means of travel to work are prone to long - relative to the typical duration of EV charging events - parking sessions at home, with $70-80 \%$ of parking events at least 200 minutes in duration. For most groups of individuals, there is approximately a $20 \%$ likelihood that their parking event will be longer than a full 24 hour period. The 'S'-shaped curve characteristic of all three charts shows that there is a cluster of parking events that are shorter in duration (0-400 minutes) and another cluster around 800-1000 minutes, which is particularly accentuated for the employed individuals who use a car to get to work either as a driver or passenger. This is thought to align with typical overnight parking events between arriving at home from work one day and driving to work again the next.

\section{Integration of UK National Travel Survey Car-Based Travel Di- aries with Distribution Network Model}

\subsection{Study Distribution Network - Glasgow Southside, UK}

The network used to instantiate an EV fleet and model the impact as a result of their charging consists of a primary substation, a high voltage $(\mathrm{HV}, 11 \mathrm{kV})$ feeder, five secondary substations and twenty-four low voltage (LV, $0.4 \mathrm{kV}$ ) circuits serving a total of 857 households. Figure 4 shows the distribution network plotted over OpenStreetMap data, showing the location of network assets. The yellow square represents the primary transformer, blue 
circles represent secondary transformers and black points represent customer endpoints. HV circuits are represented by red lines and LV circuits are coloured by circuit (and hence electrical connectivity).

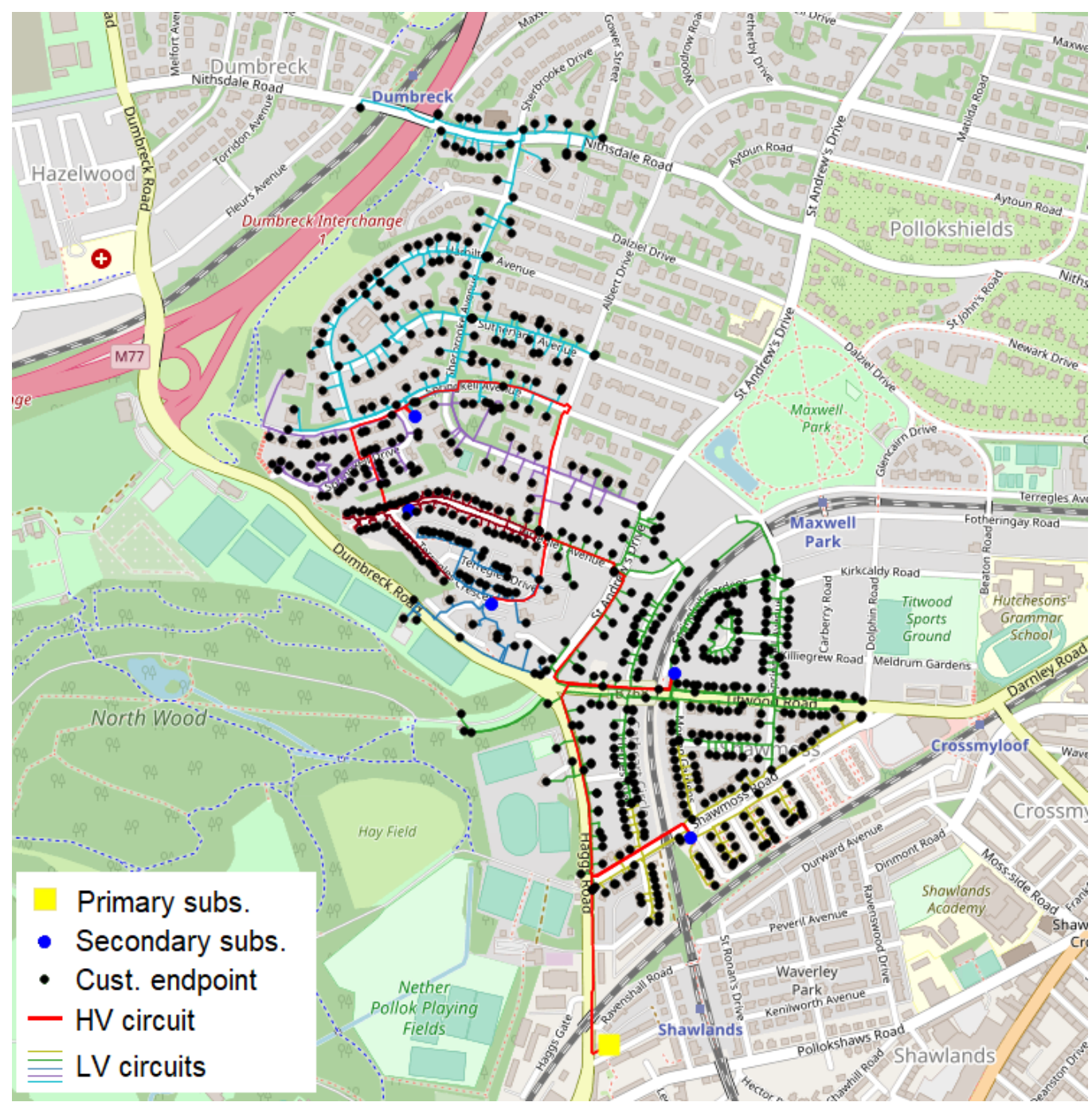

Figure 4: Glasgow Southside distribution network plotted over OpenStreetMap data showing location of network assets

\subsection{UK Census Data}

The last completed Census in the UK was in 2011. Responses to any Census question for all GB OAs are available from the UK Data Service's Infuse 
service [56]. There are two Census questions used in this study: i) the number of vehicles $(0-4+)$ at the household, and ii) the employment type/means of travel to work of individuals within the OA; a composite question based on the same attributes on which the NTS travel diaries were disaggregated in section 3 - for example (employed, car driver), (self-employed, train) or (unemployed, DNA).

Whereas the NTS employment type options are employed, self-employed and unemployed, the Census employment type contains an additional option: economically inactive. This is defined as someone who is out of work, and not actively looking for it [57] - including retirees. It is assumed in this paper that their travel habits are similar to those of the unemployed group, and the travel diaries attributed to the latter are used accordingly.

Figure 5 shows the car availability per household and the economic activity by individuals in the study network area in comparison to the Scotland average. Figure 6 shows the proportion of individuals in the study network area by economic activity and means of travel to work for each type of economic activity respectively, also in comparison to the Scotland average.

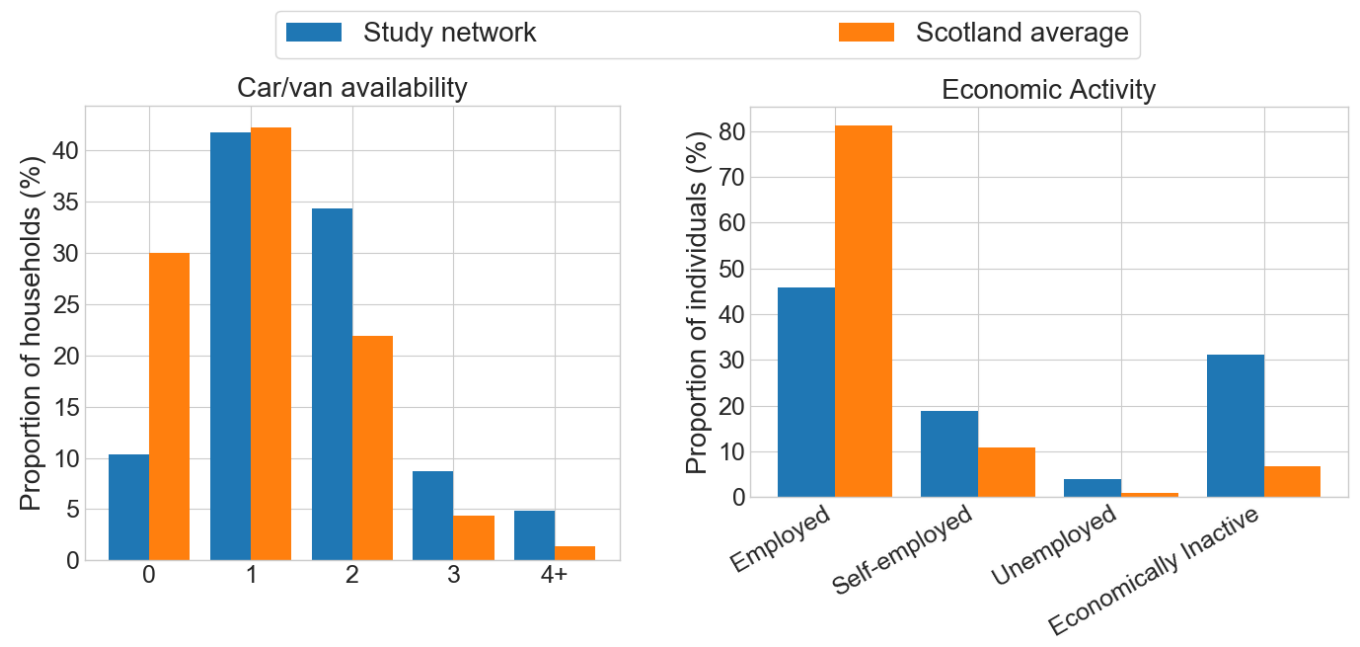

Figure 5: Proportion of households by car/van availability (left) and proportion of individuals by economic activity (right) in study network area 

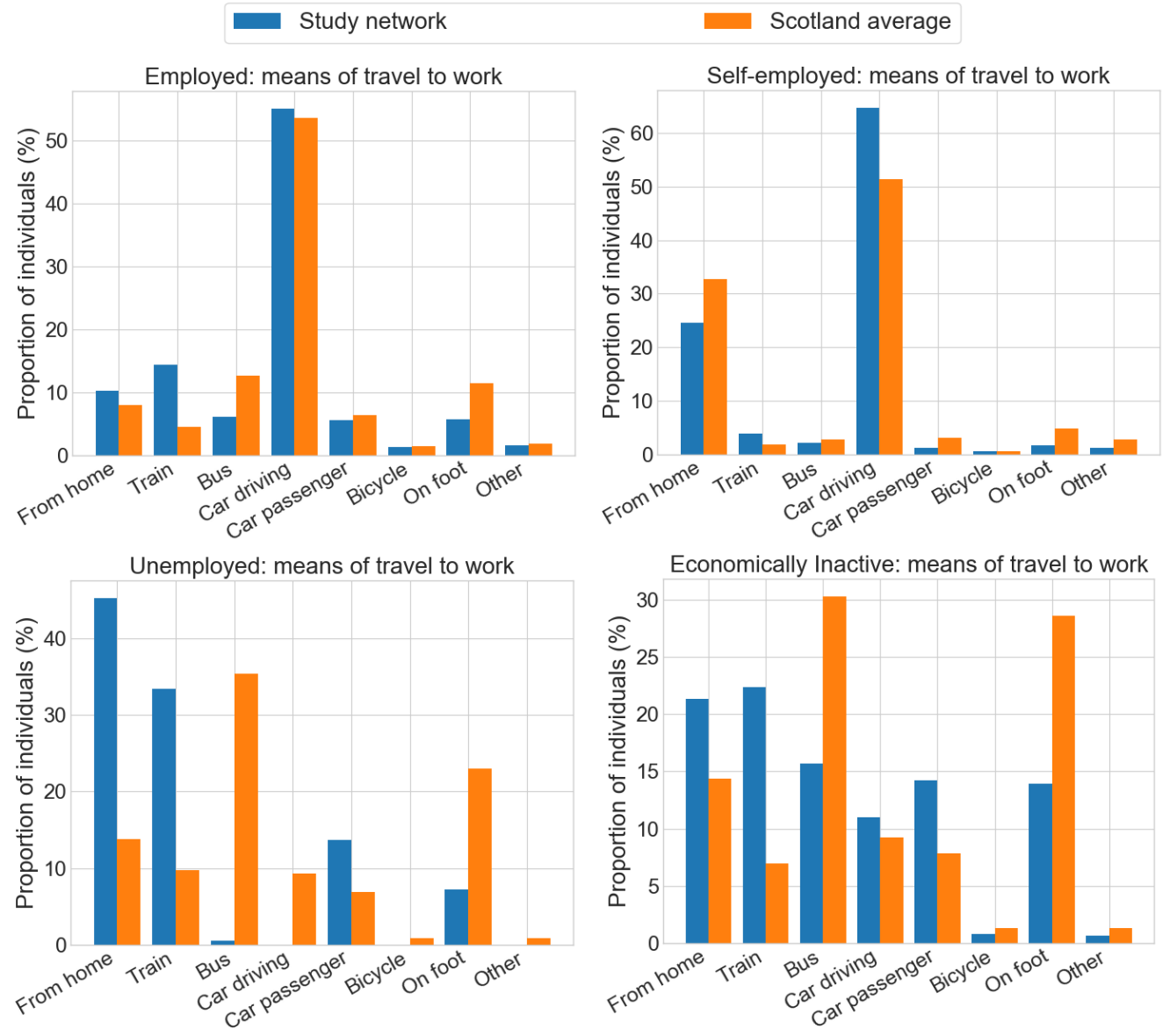

Figure 6: Proportion of individuals by means of travel to work for each type of economic activity in study network area

Figure 5 shows that the study network is characterised by a large availability of vehicles, with a proportion of households without cars almost three times less than the Scottish average, and significantly greater proportions of households with 2, 3 and $4+$ vehicles in the household. Employment is low in the area; just over half of the Scottish average and the proportions of selfemployed, unemployed and economically inactive are all significantly higher than the Scottish average. Figure 6 shows that a majority of those who are in some kind of employment (employed and self-employed) use a car to get to work, in accordance with the Scotland average data. It should be noted that whereas all NTS respondents who claimed to be unemployed answered 
'DNA' to means of travel to work, this was not an option on the Census form. A significant proportion answered 'from home', which may amount to the same thing; otherwise, it may be that they report normally travelling to work by a method when in work, and that at the time the Census was carried out they reported themselves to be unemployed or economically inactive.

\subsection{Instantiation of EV Fleet in Network}

The network data and Census data are combined to create a fleet of EVs as described in Algorithm 1. Each busbar in the network is matched with its corresponding OA, and hence distributions of responses to the two Census questions discussed are returned. These distributions are used in a MonteCarlo style approach to instantiate a fleet of EVs and assign them with travel diaries that are likely to represent the travel habits of the local population. It is assumed in this study that all vehicles present in the network according to the Census data are replaced by EVs.

In Algorithm $1, \mathbb{B}$ is the set of busbars in the network, indexed by $b$. $\mathbb{H}_{b}$ is the set of households connected to busbar $b$, indexed by $h . \mathbb{E}_{h}$ is the set of EVs at household $h$, indexed by $e$.

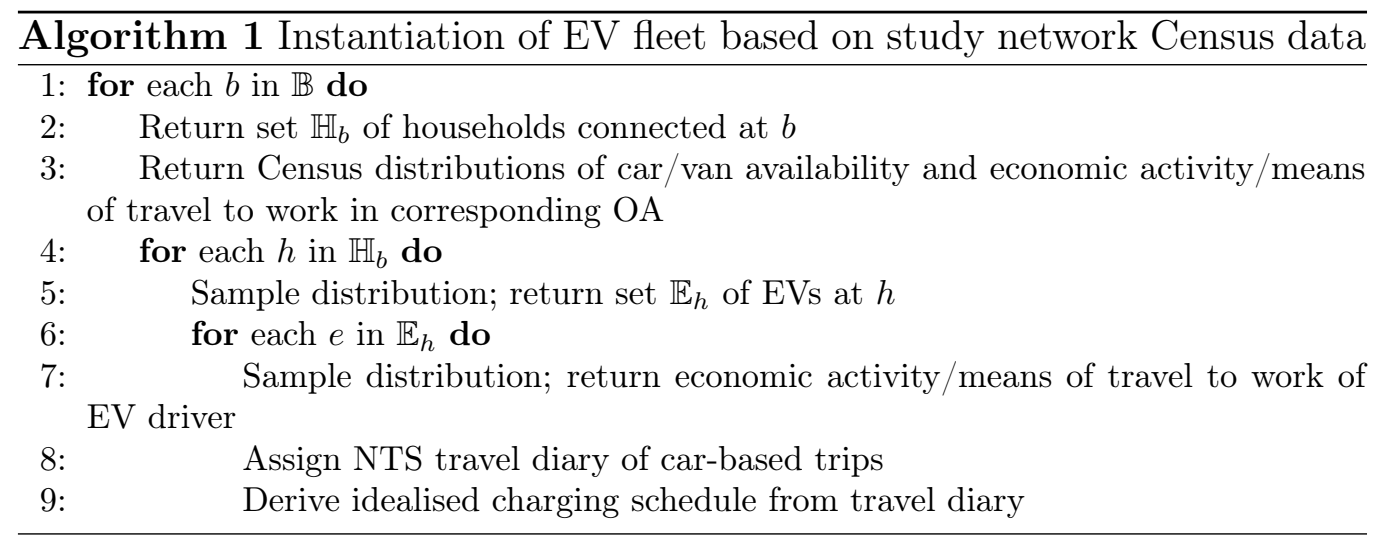

As already mentioned, there is a discrepancy in the responses of the means of travel to work question between the NTS and the Census. If a driver is returned as being in any category with zero travel diaries as in Table 3, an unemployed - DNA travel diary is assigned. It is acknowledged that the use of the DNA travel diaries in this fashion could be a source of unreliability in the analysis; however, the main differences (as shown in Figures 1-3) are between individuals who drive to work and those who do not. 
In the results presented in section 6, the process in Algorithm 1 is run for 10 trials for each combination of parameters investigated. Due to the large number of domestic premises served by the study network, there is a significant amount of averaging that takes place as the simulation is carried out. Resulting confidence intervals are shown in the results presented in section 6 .

\subsection{Domestic Demand Modelling}

To investigate the degree to which charging demand coincides with the existing domestic demand (i.e. that which exists before the introduction of EVs), a higher-order Markov chain based household energy demand model from $[58,59]$ is used to synthesise likely demand profiles for the domestic premises in the study distribution network (Figure 4). The model simulates household electricity demand based on the active occupancy of households, derived from analysis of the results of the UK Time Use Survey - a largescale household survey of more than 20,000 individuals that aims to shed light on how people in the UK spend their time [60]. The reader is directed to $[58,59,61]$ for detailed information on the domestic demand tool used in this study. As with the instantiation of EV travel diaries in the study network (Algorithm 1), this analysis was conducted on a basis of 10 Monte Carlo trials. All trials were based on a winter weekday, as to reflect the peak demand on the system and the 'worst case' as planned for by the distribution network operator. The resulting domestic demand profiles for the study network are shown in Figure 10.

\section{Derivation of EV Charging Schedules from UK National Travel Survey Data}

\subsection{Overview}

One of the most challenging aspects regarding modelling the impact of EVs on the electricity system is the impact of human behaviour, specifically how individuals decide to schedule charge events. This effectively determines the frequency, duration and energy requirement of charge events and hence their impact on the electricity system.

In this paper, a greedy heuristic algorithm originally presented in the author's earlier work [52] is used to derive 'idealised' charging schedules from NTS travel diaries (though a summary is provided in this section, the reader is referred to [52] for a detailed explanation of how the heuristic works). These 
idealised charging schedules represent a scenario in which EV charging is seen by drivers as an inconvenience, and therefore something that they would aim to minimise. In summary, the method returns the minimum number of charge events required to satisfy the energy requirements of an NTS travel diary (Table 2), choosing parked charging events first and resorting to en route charging events only when parked charging opportunities are not sufficient to meet the travel diary's energy requirements.

It is noted that the pricing of different charging types is not considered in this study, nor in the algorithm originally presented in [52]. This is expected to have a considerable effect on where people choose to charge, and is further discussed as piece of future work in section 8 .

A summary of the algorithm used is shown in Figure 7. $S^{\text {min }}$ is defined as the minimum allowable SoC that would enable the vehicle to drive a further $25 \mathrm{~km}$ on the combined level of energy consumption (Table 1), based on an assumed level of driver prudence. $S_{i}$ is the SoC after trip $i$ including the addition of any energy from parked charging after, or en route charging during, trip $i$. 


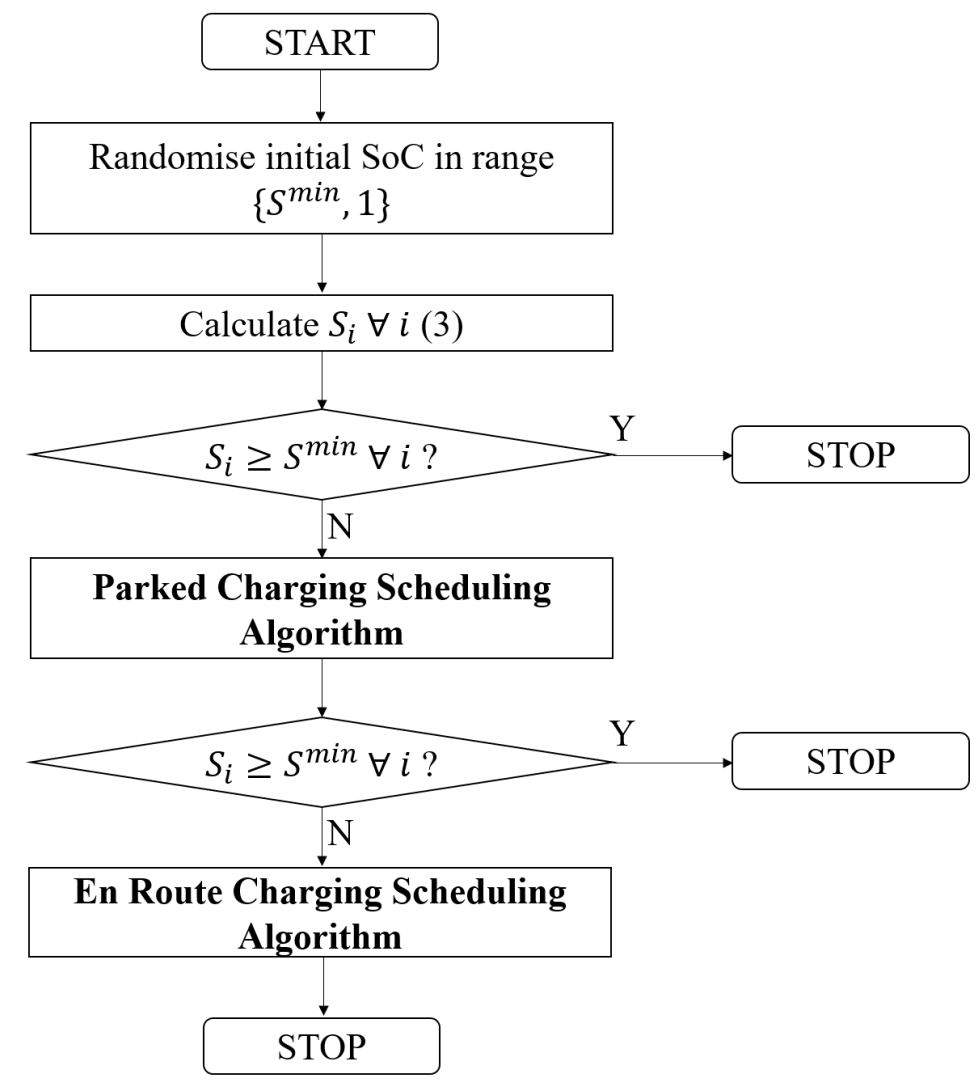

Figure 7: Summary of heuristic algorithm used to derive charging schedules from NTS travel diaries (originally from [52])

\subsection{Example Charging Schedules}

While EVs will seek to minimise the time spent en route charging, gaining only enough energy it needs to arrive at the end of the trip with the minimum permitted SoC, they will seek to gain the maximum possible from any parked charging event, subject to the charger power and a standard lithium-ion constant current - constant voltage (CC-CV) battery charging curve (Figure 8) $[62-64]$. 


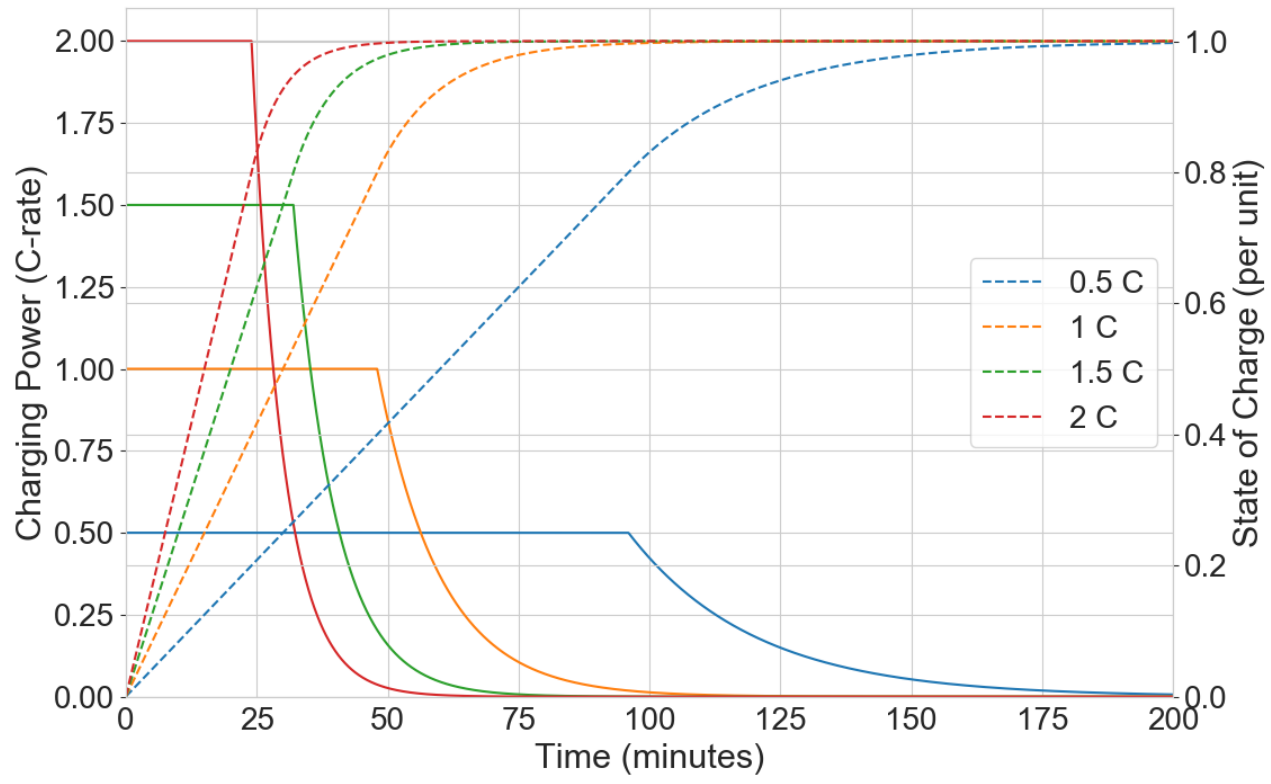

Figure 8: Battery charging profile for lithium-ion batteries for four different C-rates (i.e. charging power per unit battery capacity) — solid lines show applied power, dashed lines show battery SoC

The instantaneous power $P_{i}(t)$ of the charge event following trip $i$ at time $t$ (minutes) after the plug-in time $t_{i}^{s}$ is given in (1).

$$
P_{i}(t)= \begin{cases}P_{i}^{D C}, & t \leq t_{i}^{0.8} \\ P_{i}^{D C} e^{-\lambda_{i}\left(t-t_{i}^{0.8}\right)}, & t>t_{i}^{0.8}\end{cases}
$$

where $P_{i}^{D C}$ is the rated capacity of the charger, taken from Table 1 . Whereas en route charging is carried out using a DC charger, home and workplace/public charging is done with $\mathrm{AC}$ charging: in this case, the $\mathrm{DC}$ power the vehicle can receiver is equal to the $\mathrm{AC}$ charger power multiplied by a one-way $\mathrm{AC} / \mathrm{DC}$ conversion efficiency of $88 \%$, in accordance with empirical results presented in [63]. $t_{i}^{0.8}$ is the time in the charging event following trip $i$ at which the battery's SoC reaches 0.8 and the charging event transitions from the CC region to the $\mathrm{CV}$ region. $\lambda_{i}$ is the CV-region decay constant of charging event following trip $i$. This is derived for different battery capacities and charging power ratings by equating the area under the curve of the $\mathrm{CV}$ region in Fig- 
ure 8 to $20 \%$ of the battery capacity (for more details, the reader is referred to [52]). Values of $\lambda$ for all combinations of battery capacity and charger power used in this study are presented in Table 4.

Table 4: Decay constant $\lambda$ as used to apply charging power to network

\begin{tabular}{ll|llll}
\multicolumn{2}{c}{$\lambda\left(\mathbf{x 1 0}^{-\mathbf{3}}\right)$} & \multicolumn{5}{c}{ Charger power (AC) } \\
& & $3.7 \mathrm{~kW}$ & $7.4 \mathrm{~kW}$ & $11 \mathrm{~kW}$ & $22 \mathrm{~kW}$ \\
\hline \multirow{3}{*}{ Battery Capacity } & $24 \mathrm{kWh}$ & 11.29 & 22.59 & 33.58 & 67.16 \\
& $64 \mathrm{kWh}$ & 4.24 & 8.47 & 12.59 & 25.21 \\
& $100 \mathrm{kWh}$ & 2.71 & 5.42 & 8.06 & 16.12
\end{tabular}

$\Delta E_{i}$, the energy gained in charge event following trip $i$, is given by the area under the power curve in Figure $8(2)$.

$$
\Delta E_{i}=\int_{t_{i}^{s}}^{\min \left(t_{i}^{\infty}, t_{i}^{d}\right)} P_{i}(t) d t
$$

where $t_{i}^{d}$ is the time at which the vehicle departs the charging event following trip $i$, which is set by the departure time of its next trip, and $t_{i}^{\infty}$ is the time at which the charger switches off as the applied power has reached $1 \%$ of its rated value (at this point, the battery is considered full).

Tables 5 and 6 show idealised charging schedules as derived by the heuristic presented in [52], if those trips were taken in (for Table 5) a $24 \mathrm{kWh} \mathrm{EV}$ under the low charging power scenario with access to home charging only, and (for Table 6) a $64 \mathrm{kWh}$ EV under the high charging power scenario with access to home, work and public charging. The energy consumption values for both cases are taken from representative EV models of those battery sizes (Table 1).

In the simulation, the vehicle's SoC at the start of the travel diary is randomised between the minimum permissible - that which allows the EV a remaining range of $25 \mathrm{~km}$ on the combined energy consumption value, based on how far a prudent driver would be willing to drive before recharging - and 1, i.e. a full battery. In the examples presented in Tables 5 and 6 , the initial SoC was set at $50 \%$ to allow comparison.

In Tables 5 and $6, E^{\text {start }}$ and $E^{\text {end }}$ are the energy contents of the vehicle's battery (i.e. the SoC multiplied by the battery capacity) at the start and end of the charging event respectively. 
Table 5: Idealised charging schedule derived from NTS travel diary in Table 2 for an EV with a battery capacity of $24 \mathrm{kWh}$, low charging power scenario, $\mathrm{H} \neg \mathrm{W} \neg \mathrm{P}$ charging access

\begin{tabular}{|c|c|c|c|c|c|c|c|}
\hline $\begin{array}{l}\text { Trip } \\
\#\end{array}$ & $\begin{array}{l}\text { Charge } \\
\text { Type }\end{array}$ & $\begin{array}{l}t^{s} \quad \text { (Day, } \\
\text { HH:MM) }\end{array}$ & $\begin{array}{l}t^{d} \quad \text { (Day, } \\
\text { HH:MM) }\end{array}$ & $\begin{array}{l}E^{\text {start }} \\
(\mathbf{k W h})\end{array}$ & $\begin{array}{l}E^{e n d} \\
(\mathbf{k W h})\end{array}$ & $\begin{array}{l}P^{D C} \\
(\mathbf{k W})\end{array}$ & $\begin{array}{l}t^{0.8} \text { (Day, } \\
\text { HH:MM) }\end{array}$ \\
\hline 2 & En route & M 19:10 & M 19:12 & 4.68 & 6.07 & 50 & - \\
\hline 2 & Home & M 19:20 & M 20:15 & 4.68 & 7.67 & 3.26 & M 23:48 \\
\hline 3 & En route & M 20:38 & M 20:39 & 4.68 & 4.97 & 50 & - \\
\hline 4 & Home & M 23:00 & $\mathrm{Tu}$ 07:20 & 4.68 & 24 & 3.26 & $\mathrm{Tu}$ 03:28 \\
\hline 6 & Home & Tu 19:00 & Th 14:30 & 9.64 & 24 & 3.26 & $\mathrm{Tu} 21: 56$ \\
\hline 10 & Home & Th 21:45 & F $07: 20$ & 5.67 & 24 & 3.26 & F 01:34 \\
\hline 14 & Home & Sa $17: 00$ & $\mathrm{Su} 14: 30$ & 6.22 & 24 & 3.26 & Sa 20:59 \\
\hline
\end{tabular}

Table 6: Idealised charging schedule derived from NTS travel diary in Table 2 for an EV with a battery capacity of $64 \mathrm{kWh}$, high charging power scenario, HWP charging access

\begin{tabular}{|c|c|c|c|c|c|c|c|}
\hline $\begin{array}{l}\text { Trip } \\
\#\end{array}$ & $\begin{array}{l}\text { Charge } \\
\text { Type }\end{array}$ & $\begin{array}{l}t^{s} \quad \text { (Day, } \\
\text { HH:MM) }\end{array}$ & $\begin{array}{l}t^{d} \text { (Day, } \\
\text { HH:MM) }\end{array}$ & $\begin{array}{l}E^{\text {start }} \\
(\mathbf{k W h})\end{array}$ & $\begin{array}{l}E^{\text {end }} \\
(\mathrm{kWh})\end{array}$ & $\begin{array}{l}P^{D C} \\
(\mathrm{~kW})\end{array}$ & $\begin{array}{l}t^{0.8} \text { (Day, } \\
\text { HH:MM) }\end{array}$ \\
\hline 5 & Work & Tu 08:00 & $\mathrm{Tu} 18: 10$ & 5.38 & 64 & 19.36 & Tu 10:22 \\
\hline
\end{tabular}

By comparison of Tables 5 and 6 , the effects of changing EV parameters on the charging schedules of EVs can be seen. Whereas the $24 \mathrm{kWh}$ EV had to charge on five of the occasions when it parked and had to stop to charge en route twice due to the charging opportunities being insufficient, the $64 \mathrm{kWh}$ EV had to charge only once on the occasions when it parked and managed to avoid any en route charging stops. The higher charger power means that the duration of the CC part of the charging event (between $t^{s}$ and $t^{0.8}$ ) is significantly shorter than it would have been otherwise, allowing the vehicle to gain more energy from a charging stop of a given duration. Whereas the $24 \mathrm{kWh}$ EV could only charge at home, the $64 \mathrm{kWh}$ EV also had the option of charging at work or public destinations. It chose to charge at work, after trip 5 , rather than after any other trip because by doing so, it could defer its charging until the latest possible opportunity and take the maximum possible SoC to the end of its travel diary.

\subsection{Application of Charge Events to Network}

Time series are generated that represent the instantaneous charging demand from each vehicle in the fleet in 10 minute intervals using the data in the charging schedules produced from each travel diary (e.g. Tables 5 and 
6). For each charging event, (1) is used to apply a power at each timestep $t$. All home charging events are applied to the busbar at which the vehicle was instantiated (as in Algorithm 1). Work, public and en route charging events are assumed to take place outwith the study distribution network modelled, and are not applied in this study.

Results are presented for a two-day period from midday on the second day of the week to midday on the fourth day of the week (i.e. $12 \mathrm{pm}$ on Tuesday to $12 \mathrm{pm}$ on Thursday) to minimise any boundary effects resulting from the assumed initial SoC.

\section{Results}

\subsection{Analysis of Charge Events}

Figure 9 shows the time series of charging demand from each mode of charging, Figure 10 shows the time series of domestic demand and domestic demand plus home charging, Figure 11 shows the time series of the proportion of EVs in the network i) charging and ii) charging in the CC mode of the battery charging profile (Figure 8) and Figure 12 show the total energy extracted from each charging type over the seven day period - for all combinations of EV parameters trialled. The titles of each plot refer to the battery capacity (kWh), the charging power scenario (low/high) and level of access to charging at different locations: $\mathrm{H}, \mathrm{W}$ and $\mathrm{P}$ refer to access to charging at home, work and public destinations respectively and a negation $(\neg)$ symbol preceding any of those letters implies a lack of access to charging at that location. Charts in all figures show the spread of the results across the 10 trials carried out: in Figures 9-11, the shaded regions show the 95\% confidence intervals of the loading or charging coincidence at 10 minute intervals and the solid lines show the mean values. In Figure 12, the mean values are shown by the height of the bars; $95 \%$ confidence intervals are shown by error bars. 


\subsection{Network Loading Time Series}
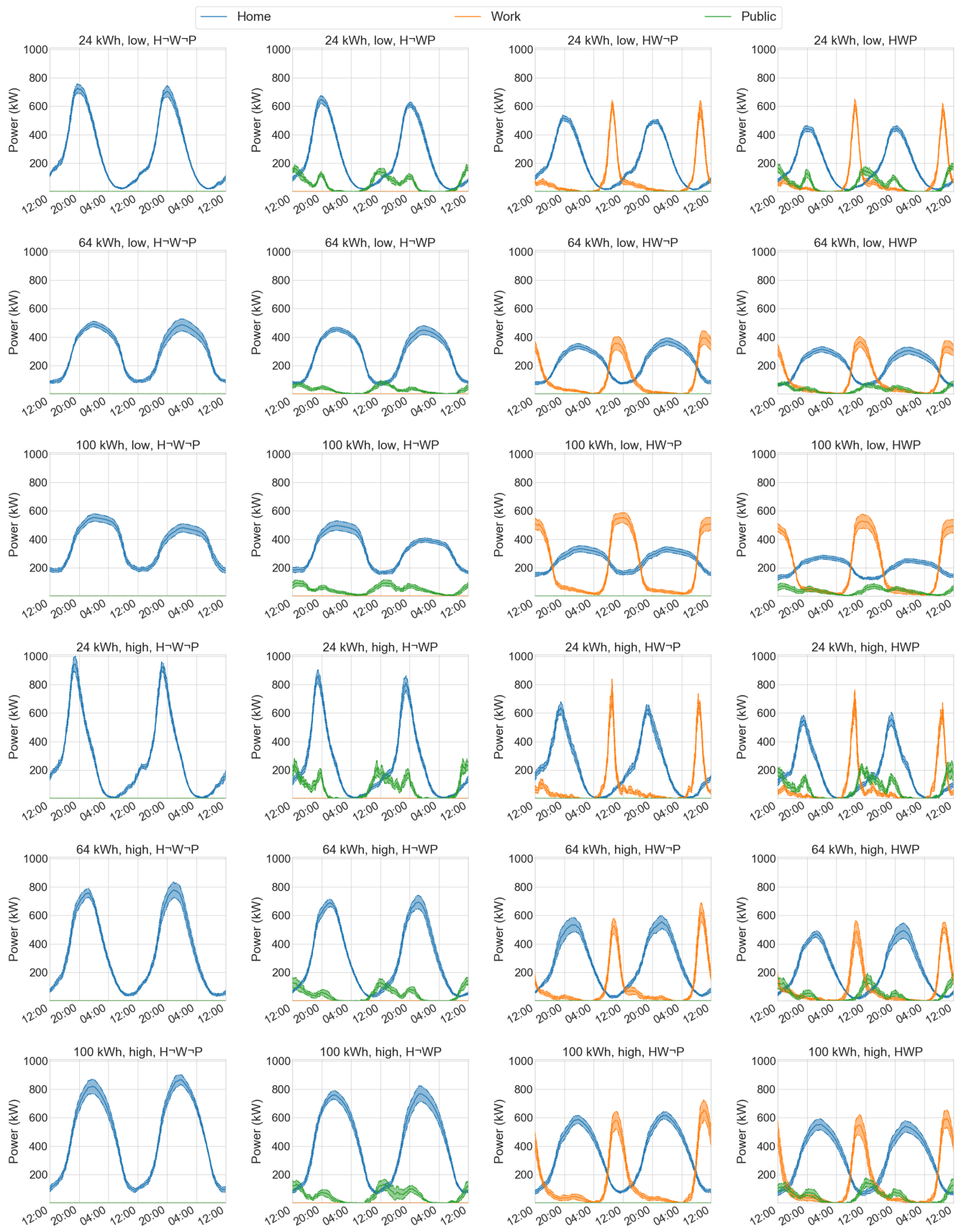

Figure 9: Time series of home, work and public charging demand for varying combinations of battery capacity, charger power and levels of access to charging at different locations 


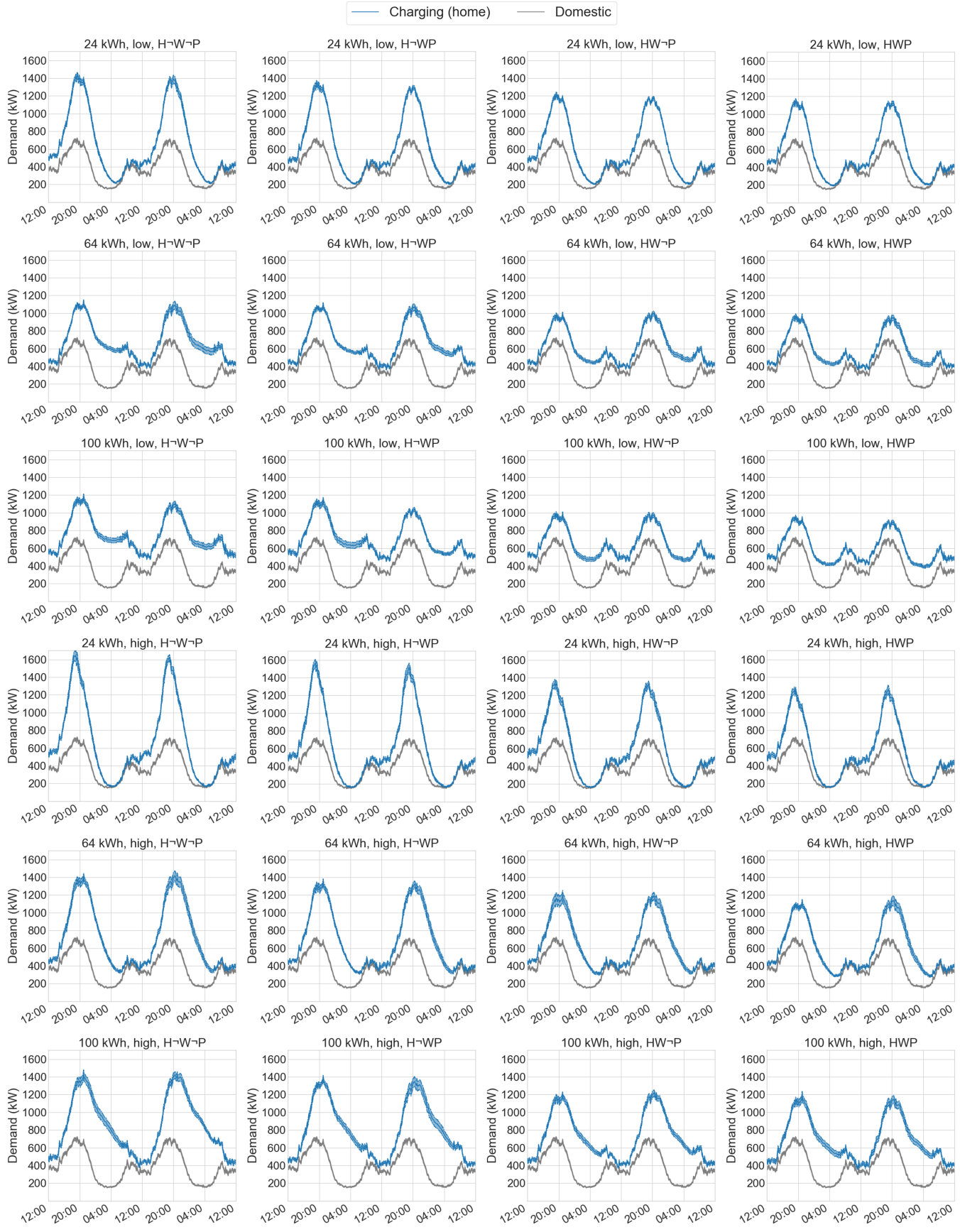

Figure 10: Time series of domestic demand and domestic plus home charging demand for varying combinations of battery capacity, charger power and levels of access to charging at different locations 


\subsection{Coincidence of Charging}
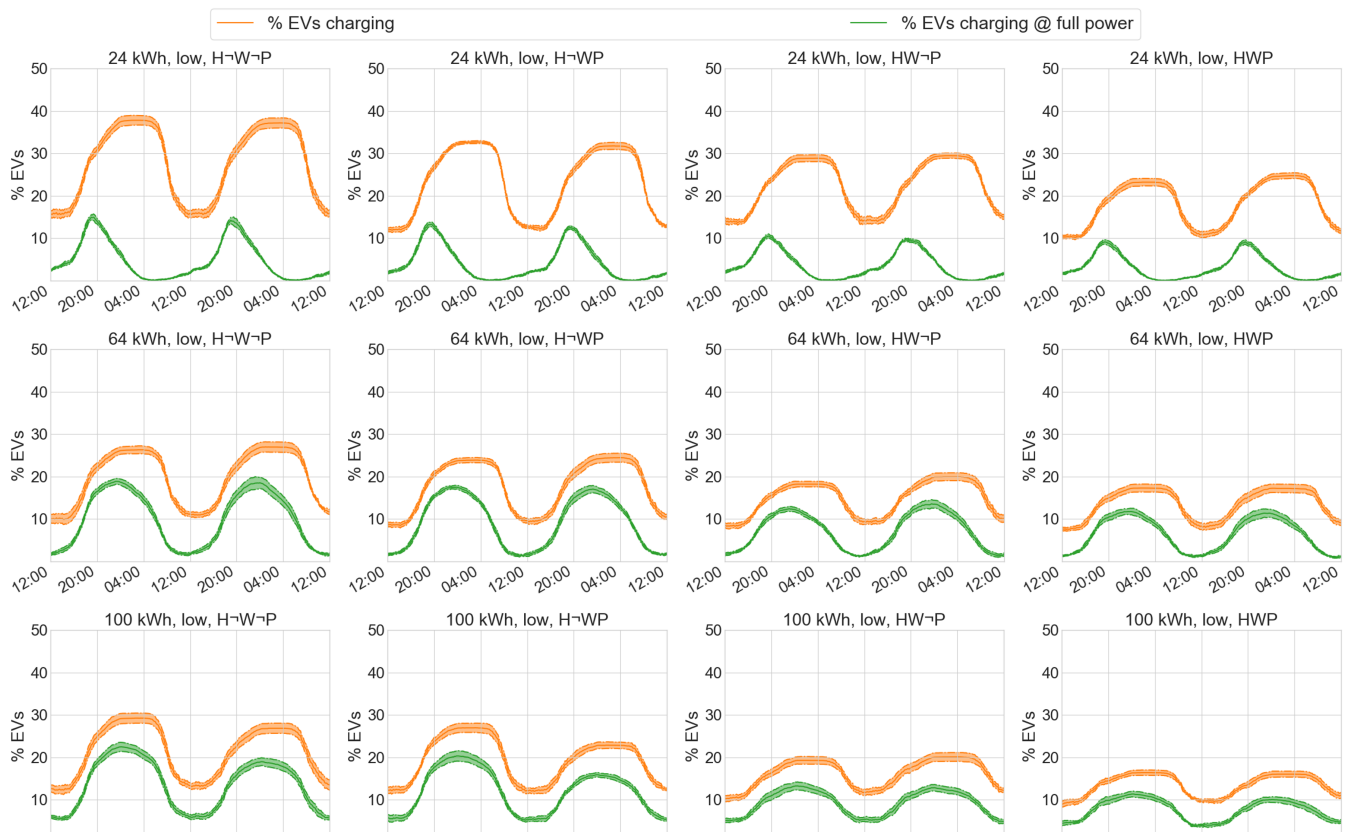

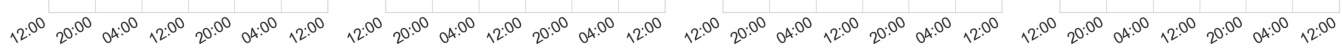
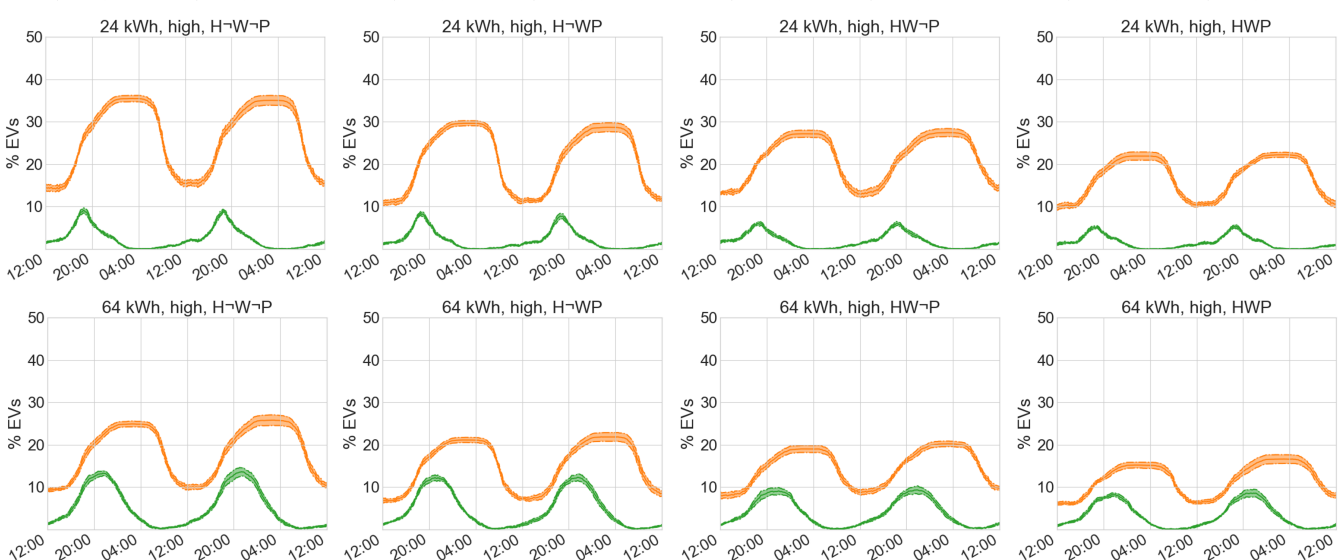

$50 \quad 64 \mathrm{kWh}$, high, HWP
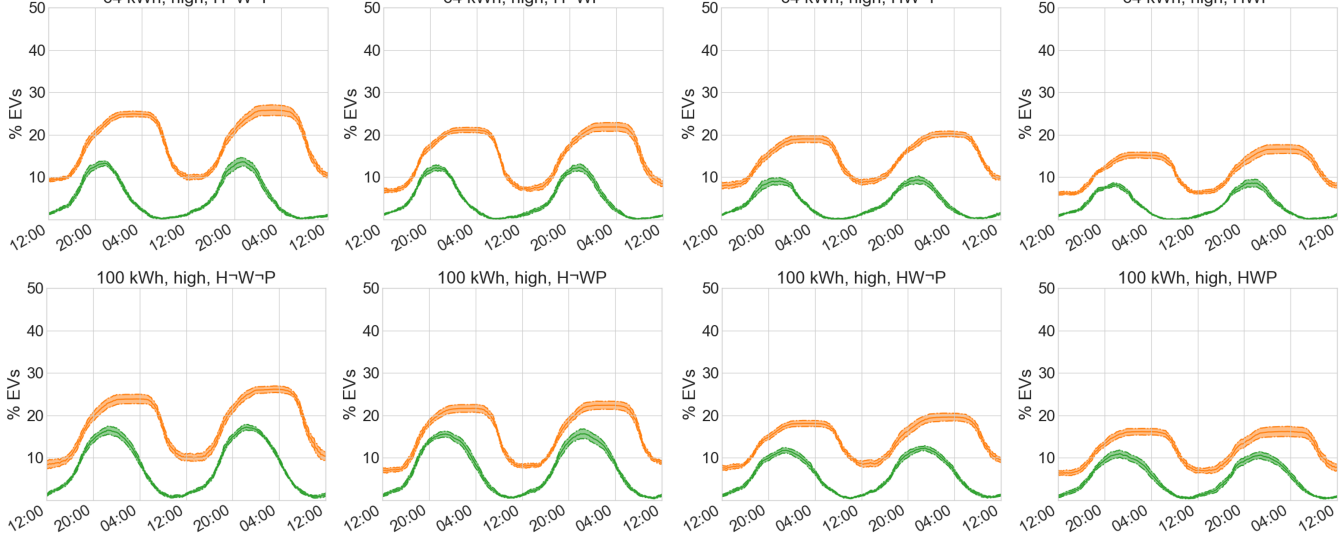

Figure 11: Coincidence of EVs charging and coincidence of EVs charging at full power for varying combinations of battery capacity, charger power and levels of access to charging at different locations 


\subsection{Energy added}
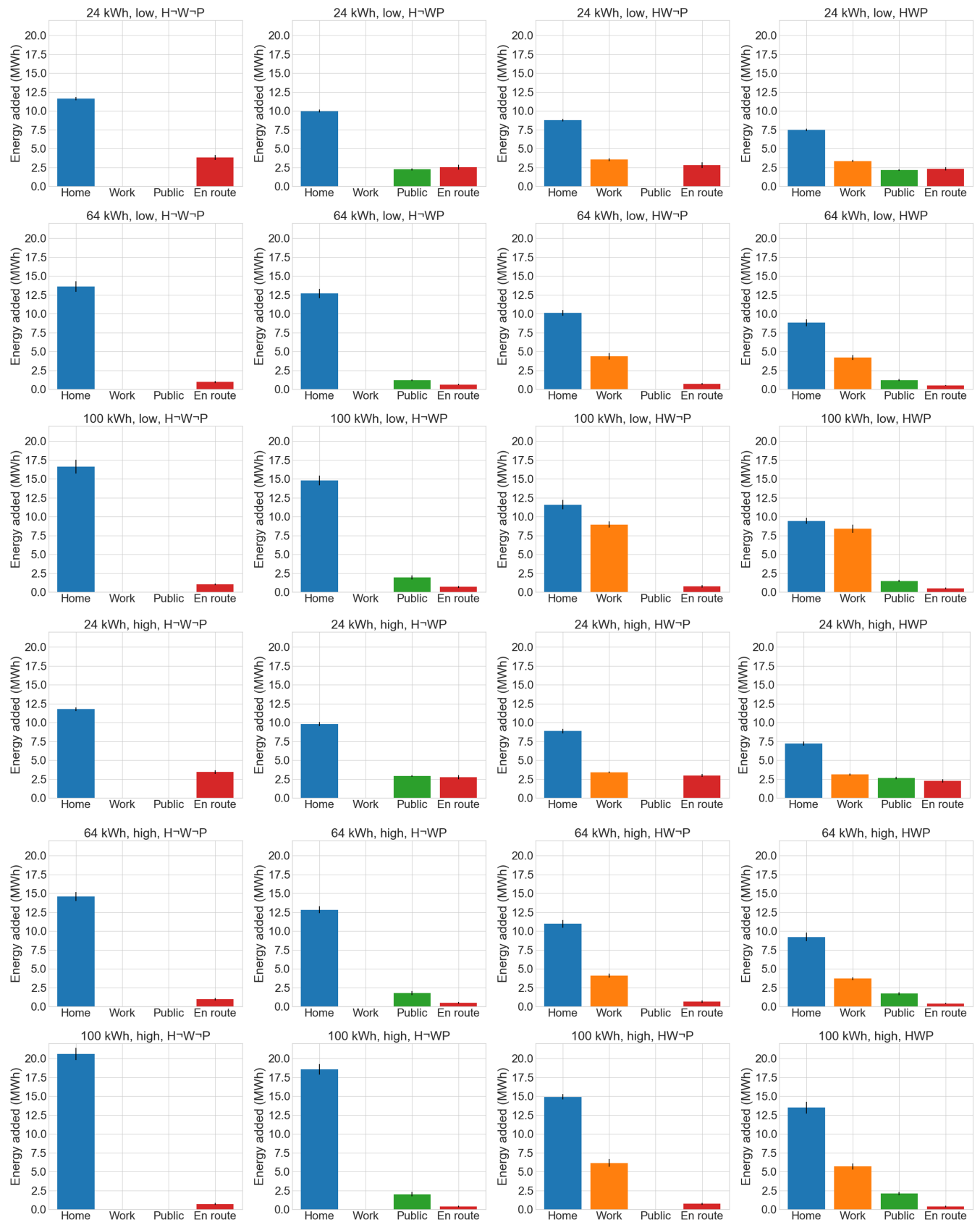

Figure 12: Total energy added to vehicles by charging at home, work, public and en route for varying combinations of battery capacity, charger power and levels of access to charging at different locations 


\section{Discussion}

\subsection{Effect of Battery Capacity}

Figure 9 shows that increasing the battery capacity for a given charger power and level of access to charging reduces the prominence and magnitude of the peak, with a $30 \%$ reduction in peak charging demand from having a fleet of $24 \mathrm{kWh}$ EVs to having a fleet of $64 \mathrm{kWh}$ EVs. Notably, the peak demand also occurs later when battery capacities are larger: using the low power, $\mathrm{H} \neg \mathrm{W} \neg \mathrm{P}$ scenario as an example, the peak demand recedes from around $8 \mathrm{pm}$ if all vehicles had $24 \mathrm{kWh}$ batteries to around midnight for both $64 \mathrm{kWh}$ and $100 \mathrm{kWh}$ cases. Figure 10 shows that increasing the battery capacity for a given charger power and level of access to charging leads to the shifting of charging demand late into the night, resulting in a higher load on the network at off-peak times.

These patterns are explained by the patterns of EVs plugging in, as shown in Figure 11. As discussed in section 5.2, EVs with larger battery sizes are expected to charge less often - but when they do charge, their energy requirement per charge event is expected to be greater. This means that the proportion of these vehicles that are charging at full power (in the $\mathrm{CC}$ region of the charging curve in Figure 8) is higher as these vehicles take longer to fill up their batteries. The result is a later peak and a smaller difference between peak and trough.

Figure 12 shows that in terms of the total energy added to the vehicles, an increasing battery capacity causes a reduction in the energy added from en route charging, as the increased driving range of the vehicles means that they are less likely to be forced to charge en route. Note that the total amount of energy varies according to (i) the particular travel diaries assigned in a given trial and (ii) the level of energy consumption for each representative vehicle (depending on the battery size) - see Table 1.

The effect of battery size on EVs' charging demand is shown to have a saturating effect; while there is a significant difference between $24 \mathrm{kWh}$ and $64 \mathrm{kWh}$, there is no discernible difference in the magnitudes of the peaks between $64 \mathrm{kWh}$ and $100 \mathrm{kWh}$. This is likely due to the relationship of the driving range of the vehicles with the distance of the trips that the vehicles actually complete. As shown in Figure 1, approximately 50-80\% (depending on economic activity and means of travel to work) of travel diaries recording

less than $200 \mathrm{~km}$ of driving distance. The relative EPA real-world ranges of the three representative vehicles used for this study are $121 \mathrm{~km}$ for the 24 
kWh Nissan Leaf, $415 \mathrm{~km}$ for the $64 \mathrm{kWh}$ Hyundai Kona and $507 \mathrm{~km}$ for the $100 \mathrm{kWh}$ Tesla Model S [54]. It is suggested that the relative frequency of parked charging opportunities with that of journeys undertaken seems to produce this saturating effect.

\subsection{Effect of Charger Power}

Figure 9 shows that increasing the charging power increases the prominence, magnitude and ramp of the peak demand for a given battery size and level of access to charging. On the other hand, the minimum charging demand is reduced: in most cases, to near-zero in the middle of the day. The timing of the peak is brought forward: using the $\mathrm{H} \neg \mathrm{W} \neg \mathrm{P}$ scenario as an example, the peak for the $24 \mathrm{kWh}$ case is brought from $8 \mathrm{pm}$ to $7 \mathrm{pm}$ and the peak for the $64 \mathrm{kWh}$ and $100 \mathrm{kWh}$ cases are brought from midnight to around $10 \mathrm{pm}$. Similar patterns are observable from Figure 10: an increase in charging power brings charging demand forward to be coincident with the existing domestic demand peak, resulting in the highest overall demand to the network coming from a fleet of EVs with $24 \mathrm{kWh}$ batteries, high charging power and access to charging at home only.

Figure 11 shows that the proportion of EVs charging through the night is expected to reduce slightly if charging power is increased, and the proportion of EVs charging at full power is expected to reduce significantly. This is because vehicles will fully charge their batteries in a shorter time if they have access to a higher charger power.

Figure 12 shows that there is no significant change in the energy added to vehicles when changing the charging power. This suggests that the majority of parked charging events are long enough to fill the vehicles' batteries even with the low power charging scenario.

\subsection{Effect of Charging Access}

It is shown in Figure 9 that increasing the level of access of charging at different locations can significantly reduce the home charging peak, and thus the peak that the study network concerned would experience, as shown in Figure 10. This is done at the expense of an increase in demand in work and public location charging. Of particular interest is workplace charging, which in most scenarios is seen to be the new peak demand of all charging modes. This is due to the generally smaller variance in the time of arrival at work compared to the time of arrival at public places. 
Figure 11 shows that being able to charge at other locations significantly reduces the proportion of EVs charging at home overnight; a similar effect is observable on those charging at full power.

Figure 12 shows that increasing the number of locations that individuals can charge at spreads the energy added across different charging types. A reduction in en route charging is seen, due to individuals being less likely to have long stretches without parked charging opportunities. It is shown that as when the en route charging energy reaches a certain level, it does not get any smaller. It is suggested that this is due to the presence of long journeys, which outstrip the range of vehicles and force them to stop and charge. Home charging remains the majority of charging for all cases, which is in line with predictions made in [8].

\subsection{Discussion of Results in Context of EV Markets and Electricity Net- works}

As already discussed in section 1.1, it is proposed that EV parameters and the resulting impact to the electricity system - as characterised by Figures 9-12 - will move towards increasing battery capacity, increasing charging power and access to charging at more locations.

GB peak domestic electricity demand generally occurs between 6-7 pm when cooking, lighting and audiovisual demands are increased generally when people get home from work [65-67]. Therefore, EV charging will have the greatest network impact when the peak demand from charging coincides with the peak domestic demand. Figure 9 shows that an increase in battery capacity could make it easier for distribution networks to provide for peak EV charging demand, given that it is more likely to occur later on when domestic demand is lower. Increasing charger power, however, could bring greater challenges to the distribution system as the peak from EV charging is seen to increase significantly. Aside from providing a means of charging for those who lack access to charging at home, the results presented should provide a mandate for increasing the penetration of workplace and public destination charging as a method of reducing the latent peak demand on residential-dominated distribution networks.

The results presented are based on the overarching assumption that the primary driver of individuals' behaviour is to minimise the number of charging events required to cover the energy requirements of a set of journeys. While this may be reasonable to assume in a system where individuals pay a constant rate for their vehicle charging, and indeed some of these effects 
have been noted in EV trials [51], a different set of behaviours are expected to emerge if there are variable prices applied to EV charging. For example, in a Vehicle 2 Grid scheme whereby the owner is remunerated for having a portion of their vehicle's battery accessible - generally speaking by an aggregator to participate in the provision of grid services such as energy arbitrage or frequency response, the user is effectively incentivised to plug their vehicle in more often. In this scenario, the EV could be seen as a flexible resource rather than simply a demand to be met.

\section{Conclusions and Future Work}

This paper has presented analysis of the likely impact of three key EV parameters - battery capacity, charger power and the set of locations at which the EV can charge - on the resulting charging demand of a fleet of EVs instantiated using data from a real GB distribution network and corresponding demographic data from the UK Census, in doing so presenting a method for characterising EV charging demand based on key demographic indicators relating to the population of individuals served by a particular network. Out of the key emerging patterns identified in the evolving EV market, increasing battery capacities and the establishment of more widespread charging opportunities may reduce the peak demand from EV charging or shift it to a time less likely to coincide with peak domestic demand, hence making it easier for the network to cope with increasing penetrations of EVs. On the other hand, increasing charging power may increase the peak and bring it closer to a time where it is more likely to coincide with peak domestic demand, thus making it more difficult for the network to cope.

As mentioned already in section 5, the pricing of different charge types and the resulting effect on how drivers charge their vehicles has not been considered in this study. It is recommended that future work be conducted as to what the likely effect on pricing could be on how drivers charge, and what the resulting impact on the electricity system could be.

It is now mandated (as of July 2019) that every installation of EV charging infrastructure eligible for government grants in the UK should be 'smart', i.e. 'have the capability to receive, interpret and react to a signal' [68]. However, it is not yet clear how this will be done or upon what set of technologies it will be based. Therefore, the methodology and results presented in this paper are valuable to network owners, regulators and policymakers as it sets the likely temporal variation in energy demand that will be placed on 
distribution networks if the focus of the future transport system relies on significant penetrations of battery EVs. With regards to the future potential of 'smart' charging to minimise the impact of EV charging on networks, the work presented in this paper lends itself particularly well to a piece of future work investigating the extent to which EV charging can be controlled within the constraints of an electricity network, bearing in mind the demographic spread of the individuals served by it and given likely scenarios pertaining to the spread in EV parameters.

\section{Acknowledgement}

This work has been done through the Engineering and Physical Sciences Research Council (EPSRC) Centre for Doctoral Training on Future Power Networks and Smart Grids at the University of Strathclyde, funded by grant EP/L015471/1. Grateful thanks are expressed to SP Energy Networks and Ciaran Higgins for provision of the Glasgow Southside distribution network data.

\section{References}

[1] Committee on Climate Change, "Net Zero: The UK's contribution to stopping global warming," Tech. Rep. May, 2019.

[2] World Bank and PRTM Management Consultants Inc, The China New Energy Vehicles Program, 2011, no. April. [Online]. Available: http://documents.worldbank.org/curated/en/2011/04/14082658/chinanew-energy-vehicles-program-challenges-opportunities

[3] Office of Energy Efficiency \& Renewable Energy, "Electric Vehicles: Tax Credits and Other Incentives," 2019. [Online]. Available: http://bit.ly/2HgVUQt

[4] SP Energy Networks, "NIA Annual Report," Tech. Rep., 2018. [Online]. Available: http://bit.ly/30GteYF

[5] Ofgem, "Future Insight Series: Implications of the transition to Electric Vehicles," Tech. Rep., 2018. [Online]. Available: https://bit.ly/2KjVM4I

[6] UK Parliament, "Electric vehicles: driving the transition: Government Response to the Committee's Fourteenth Report of Session 2017-19," 2019. [Online]. Available: https://bit.ly/2OHChqQ 
[7] Committee on Climate Change, "Plugging the gap: What next for Britain's EV public charging network?" 2018. [Online]. Available: https://bit.ly/2CDRS3V

[8] Department for Transport, "The Road to Zero," p. 82, 2018. [Online]. Available: https://goo.gl/KZAto2

[9] Nissan, "Leaf," 2017. [Online]. Available: https://goo.gl/W1byqZ

[10] Renault, "Zoe," 2017. [Online]. Available: https://goo.gl/xZ9rcg

[11] Mitsubishi, "i-MiEV," 2019. [Online]. Available: https://bit.ly/2RTvawd

[12] Hyundai, "Kona Electric," 2019. [Online]. Available: http://bit.ly/2K2dDO3

[13] Tesla, "Model 3," 2019. [Online]. Available: http://bit.ly/2WhRK3y

[14] Parkers, "Volkswagen ID.3 review," 2019. [Online]. Available: https://bit.ly/31TYPqb

[15] Tesla, "Model S," 2019. [Online]. Available: https://goo.gl/zKF5c7

[16] International Energy Agency, "Global EV Outlook 2019," Paris, Tech. Rep., 2019. [Online]. Available: https://bit.ly/2MwfSuV

[17] EV One Stop, "WALLPOD: EV Charging Unit, Type 1 Tethered - 16/32 AMP (3.6/7.2KW)." [Online]. Available: https://bit.ly/2Mh1T9O

[18] M. Jha, F. Blaabjerg, M. A. Khan, V. S. B. Kurukuru, and A. Haque, "Intelligent Control of Converter for Electric Vehicles Charging Station," Energies, vol. 12, no. 2334, 2019.

[19] F. Un-Noor, S. Padmanaban, L. Mihet-Popa, M. N. Mollah, and E. Hossain, "A comprehensive study of key electric vehicle (EV) components, technologies, challenges, impacts, and future direction of development," Energies, vol. 10, no. 8, pp. 1-82, 2017.

[20] D. P. Tuttle and K. M. Kockelman, "Electrified Vehicle Technology Trends, Infrastructure Implications, And Cost Comparisons," Journal of the Transportation Research Forum, vol. 51, no. 1, pp. 35-51, 2012. 
[21] Z. Lin and D. L. Greene, "Promoting the market for plug-in hybrid and battery electric vehicles," Transportation Research Record, no. 2252, pp. 49-56, 2011.

[22] Pod-Point, "Lidl Rapid Charging Stations," 2019. [Online]. Available: http://bit.ly/2YXdOh8

[23] BBC News, "Tesco and VW plan free electric car charging points," 2018. [Online]. Available: https://bbc.in/2QguHks

[24] Zap-Map, "Morrisons to install GeniePoint rapid chargers," 2019. [Online]. Available: http://bit.ly/2KAA9vP

[25] D. Stead, "Relationships between land use, socioeconomic factors, and travel patterns in Britain," Environment and Planning B: Planning and Design, vol. 28, no. 4, pp. 499-528, 2001.

[26] B. Friedman, S. P. Gordon, and J. B. Peers, "Effect of Neotraditional Neighborhood Design on Travel Characteristics," Transportation Research Record, no. 1466, pp. 63-70, 1994. [Online]. Available: http://trid.trb.org/view.aspx?id=425323

[27] S. Hanson, "The determinants of daily travel-activity patterns: Relative location and sociodemographic factors," Urban Geography, vol. 3, no. 3, pp. 179-202, 1982. [Online]. Available: https://doi.org/10.2747/02723638.3.3.179

[28] R. C. Leou, C. L. Su, and C. N. Lu, "Stochastic analyses of electric vehicle charging impacts on distribution network," IEEE Transactions on Power Systems, vol. 29, no. 3, pp. 1055-1063, 2014.

[29] J. Dunckley and G. Tal, "Plug-In Electric Vehicle Multi-State Market and Charging Survey," Tech. Rep., 2016.

[30] S. Huang and D. Infield, "The impact of domestic plug-in hybrid electric vehicles on power distribution system loads," 2010 International Conference on Power System Technology: Technological Innovations Making Power Grid Smarter, POWERCON2010, pp. 1-7, 2010. 
[31] S. Shafiee, M. Fotuhi-Firuzabad, and M. Rastegar, "Investigating the impacts of plug-in hybrid electric vehicles on power distribution systems," IEEE Transactions on Smart Grid, vol. 4, no. 3, pp. 1351-1360, 2013 .

[32] Y. Mu, J. Wu, N. Jenkins, H. Jia, and C. Wang, "A SpatialTemporal model for grid impact analysis of plug-in electric vehicles," Applied Energy, vol. 114, pp. 456-465, 2014. [Online]. Available: http://dx.doi.org/10.1016/j.apenergy.2013.10.006

[33] E. Veldman and R. A. Verzijlbergh, "Distribution grid impacts of smart electric vehicle charging from different perspectives," IEEE Transactions on Smart Grid, vol. 6, no. 1, pp. 333-342, 2015.

[34] A. Lojowska, D. Kurowicka, G. Papaefthymiou, and L. Van Der Sluis, "Stochastic Modeling of Power Demand due to EVs Using Copula," IEEE Transactions on Power Systems, vol. 27, no. 4, pp. 1960-1968, 2012.

[35] J. C. Kelly, J. S. MacDonald, and G. A. Keoleian, "Time-dependent plug-in hybrid electric vehicle charging based on national driving patterns and demographics," Applied Energy, vol. 94, pp. 395-405, 2012. [Online]. Available: http://dx.doi.org/10.1016/j.apenergy.2012.02.001

[36] E. Xydas, C. Marmaras, L. M. Cipcigan, N. Jenkins, S. Carroll, and M. Barker, "A data-driven approach for characterising the charging demand of electric vehicles: A UK case study," Applied Energy, vol. 162, pp. 763-771, 2016. [Online]. Available: http://dx.doi.org/10.1016/j.apenergy.2015.10.151

[37] M. Neaimeh, R. Wardle, A. M. Jenkins, J. Yi, G. Hill, P. F. Lyons, Y. Hübner, P. T. Blythe, and P. C. Taylor, "A probabilistic approach to combining smart meter and electric vehicle charging data to investigate distribution network impacts," Applied Energy, vol. 157, pp. 688-698, 2015. [Online]. Available: http://dx.doi.org/10.1016/j.apenergy.2015.01.144

[38] J. Brady and M. O'Mahony, "Modelling charging profiles of electric vehicles based on real-world electric vehicle charging data," Sustainable 
Cities and Society, vol. 26, pp. 203-216, 2016. [Online]. Available: http://dx.doi.org/10.1016/j.scs.2016.06.014

[39] C. C. Rolim, G. N. Gonçalves, T. L. Farias, and Ó. Rodrigues, "Impacts of electric vehicle adoption on driver behavior and environmental performance," vol. 54, pp. 706-715. [Online]. Available: http://dx.doi.org/10.1016/j.sbspro.2012.09.788

[40] M. Helmbrecht, C. Olaverri-Monreal, K. Bengler, R. Vilimek, and A. Keinath, "How electric vehicles affect driving behavioral patterns," IEEE Intelligent Transportation Systems Magazine, vol. 6, no. 3, pp. $22-32,2014$.

[41] ACEA, "Vehicles in use Europe 2018," Tech. $\quad$ Rep., $2019 . \quad$ [Online]. Available: https://www.acea.be/uploads/statistic_documents/ACEA_Report_Vehicles_in_useEurope_2017.pdf

[42] A. P. Robinson, P. T. Blythe, M. C. Bell, Y. Hübner, and G. A. Hill, "Analysis of electric vehicle driver recharging demand profiles and subsequent impacts on the carbon content of electric vehicle trips," Energy Policy, vol. 61, pp. 337-348, 2013. [Online]. Available: http://dx.doi.org/10.1016/j.enpol.2013.05.074

[43] P. Papadopoulos, S. Skarvelis-Kazakos, I. Grau, L. Cipcigan, and N. Jenkins, "Electric vehicles' impact on British distribution networks," IET Electrical Systems in Transportation, vol. 2, no. 3, p. 91, 2012. [Online]. Available: https://digitallibrary.theiet.org/content/journals/10.1049/iet-est.2011.0023

[44] G. A. Putrus, P. Suwanapingkarl, D. Johnston, E. C. Bentley, and M. Narayana, "Impact of electric vehicles on power distribution networks," 5th IEEE Vehicle Power and Propulsion Conference, VPPC '09, pp. 827-831, 2009.

[45] P. Richardson, D. Flynn, and A. Keane, "Impact assessment of varying penetrations of electric vehicles on low voltage distribution systems," IEEE PES General Meeting, PES 2010, pp. 1-6, 2010. 
[46] S. Shao, M. Pipattanasomporn, and S. Rahman, "Challenges of PHEV penetration to the residential distribution network," 2009 IEEE Power and Energy Society General Meeting, PES '09, pp. 1-8, 2009.

[47] K. Clement, E. Haesen, and J. Driesen, "Stochastic analysis of the impact of plug-in hybrid electric vehicles on the distribution grid," vol. 25, no. 1, pp. 160-160, 2009.

[48] L. Pieltain Fernández, T. Gómez San Román, R. Cossent, C. Mateo Domingo, and P. Frías, "Assessment of the impact of plug-in electric vehicles on distribution networks," IEEE Transactions on Power Systems, vol. 26, no. 1, pp. 206-213, 2011.

[49] O. Sundström and C. Binding, "Flexible charging optimization for electric vehicles considering distribution grid constraints," IEEE Transactions on Smart Grid, vol. 3, no. 1, pp. 26-37, 2012.

[50] K. P. Schneider, B. A. Mather, B. C. Pal, C. W. Ten, G. J. Shirek, H. Zhu, J. C. Fuller, J. L. R. Pereira, L. F. Ochoa, L. R. de Araujo, R. C. Dugan, S. Matthias, S. Paudyal, T. E. McDermott, and W. Kersting, "Analytic Considerations and Design Basis for the IEEE Distribution Test Feeders," IEEE Transactions on Power Systems, vol. PP, no. 99, pp. 1-1, 2017.

[51] Western Power Distribution, "Electric Nation Smart Charged Conference Review," 2019. [Online]. Available: http://bit.ly/2yXDrEc

[52] J. Dixon, P. B. Andersen, K. Bell, and C. Træholt, "On the ease of being green: An investigation of the inconvenience of electric vehicle charging," Applied Energy, vol. 258, 2020. [Online]. Available: https://doi.org/10.1016/j.apenergy.2019.114090

[53] European Court of Auditors, "The EU's response to the "dieselgate" scandal," Tech. Rep. February, 2019. [Online]. Available: https://bit.ly/2Sl0tkk

[54] United States Environmental Protection Agency, "Data on Cars used for Testing Fuel Economy," 2019. [Online]. Available: https://goo.gl/jwrFQm 
[55] UK Data Service, "UK National Travel Survey 2002-2016," 2019. [Online]. Available: https://goo.gl/LgtfDd

[56] — - "Infuse - access 2011 and 2001 UK Census data." [Online]. Available: http://infuse.ukdataservice.ac.uk/

[57] Office for National Statistics, "Economic Inactivity," 2018. [Online]. Available: http://bit.ly/321xSBu

[58] G. Flett and N. Kelly, "An occupant-differentiated, higher-order Markov Chain method for prediction of domestic occupancy," Energy and Buildings, vol. 125, pp. 219-230, 2016.

[59] —_, "A disaggregated, probabilistic, high resolution method for assessment of domestic occupancy and electrical demand," Energy and Buildings, vol. 140, pp. 171-187, 2017.

[60] Centre for Time Use Research, "United Kingdom Time Use Survey, 2014-2015." [Online]. Available: https://goo.gl/C6pMF6

[61] G. Flett, "Modelling and Analysis of Energy Demand Variation and Uncertainty in Small-Scale Domestic Energy Systems," Ph.D. dissertation, 2017. [Online]. Available: https://bit.ly/2Yqbcby

[62] M. Tabari and A. Yazdani, "An Energy Management Strategy for a DC Distribution System for Power System Integration of Plug-In Electric Vehicles," IEEE Transactions on Smart Grid, no. 2, pp. 659-668. [Online]. Available: https://doi.org/10.1109/TSG.2015.2424323

[63] F. Marra, G. Y. Yang, C. Træ holt, E. Larsen, C. N. Rasmussen, and S. You, "Demand profile study of battery electric vehicle under different charging options," IEEE Power and Energy Society General Meeting. [Online]. Available: http://dx.doi.org/10.1109/PESGM.2012.6345063

[64] M. Gjelaj, S. Hashemi, P. B. Andersen, and C. Træholt, "Grid Services Provision from Batteries within Charging Stations by using a Stochastic Planning Method of the EVs Demand Grid Services Provision from Batteries within Charging Stations by using a Stochastic Planning Method of the EVs Demand," 2019. 
[65] Department of Energy \& Climate Change, "The impact of changing energy use patterns in buildings on peak electricity demand in the UK," Tech. Rep. 243 752, 2008.

[66] Element Energy and Department of Energy \& Climate Change, "Correlation of Consumption with Low Carbon Technologies," Tech. Rep., 2014. [Online]. Available: https://bit.ly/21Q5Fxb

[67] Department of Energy \& Climate Change, "Powering the Nation 2," Tech. Rep., 2014. [Online]. Available: http://bit.ly/2KVWlAW

[68] HM Government and Department for Transport, "Electric Vehicle Smart Charging," Tech. Rep. July, 2019. [Online]. Available: http://bit.ly/2Z3vX1Z 